\title{
Flow Regimes of Air-Water Counterflow Through Cross Corrugated Parallel Plates*
}

\author{
Valmor F. de Almeida and Cyrus K. Riahi-Nezhad \\ Chemical Technology Division \\ OAK Ridge National Laboratory \\ OAK RIDGE, TN 37831-6224, U.S.A.
}

Technical Report ORNL/TM-2000/101

14 April 2000

*Submitted to the journal Separation Science and Technology 1999. Also available under request to dealmeidav@ornl.gov or at URL: http://www-smpr.ct.ornl.gov/ dalmeida. 


\begin{abstract}
Heretofore unknown flow regimes of air-water counterflow through a pair of transparent vertical parallel cross corrugated plates were observed via high-speed video. Air flows upward driven by pressure gradient and water, downward driven by gravity. The crimp geometry of the corrugations was drawn from typical corrugated sheets used as filling material in modern structured packed towers. Four regimes were featured, namely, rivulet, bicontinuous, flooding fronts, and flooding waves. It is conceivable that the regimes observed might constitute the basis for understanding how gas and liquid phases contend for available space in the interstices of structured packings in packed towers. Flow regime transitions were expressed in terms of liquid load (liquid superficial velocity) and gas flow factor parameters commonly used in pressure drop and capacity curves. We have carefully examined the range of parameters equivalent to the ill-understood high-liquid-flow operation in packed towers. More importantly, our findings should prove valuable in validating improved first-principles modeling of gas-liquid flows in these industrially important devices.
\end{abstract}




\section{Contents}

List of figures

List of tables $\quad$ iii

1 Introduction 1

2 Experimental apparatus 2

3 Geometrical quantities, characteristic units, dimensionless parameters and industrial measures 12

$\begin{array}{lll}4 & \text { Measurements and procedures } & 17\end{array}$

5 Flow regimes $\quad 19$

5.1 Rivulet regime. . . . . . . . . . . . . . . . . . . 20

5.2 Transition from rivulet to bicontinuous regime . . . . . . . . . . . 22

5.3 Bicontinuous regime . . . . . . . . . . . . . . . . 22

5.4 Flooding-fronts regime . . . . . . . . . . . . . . . . . . . . . . . . . . . . . . . . .

5.5 Flooding-waves regime . . . . . . . . . . . . . . . . . . . . 27

5.6 Flow regime map . . . . . . . . . . . . . . . . . . . . . . . . 29

6 Conclusions and final remarks $\quad 29$

$\begin{array}{ll}\text { Acknowledgments } & 33\end{array}$

$\begin{array}{ll}\text { References } & 33\end{array}$ 


\section{List of Figures}

2.1 Sketch of experimental set-up . . . . . . . . . . . . . . 3

2.2 Parallel corrugated plates set-up . . . . . . . . . . . . . 4

2.3 Construction of the corrugated plates; first step . . . . . . . . 5

2.4 Construction of the corrugated plates; second step . . . . . . . . 6

2.5 Attachment of the corrugated plates . . . . . . . . . 8

2.6 Top view of shoulder attachment $\ldots \ldots \ldots \ldots$

2.7 Side view of shoulder attachment . . . . . . . . . . . . . . 10

2.8 Water distributor wedge . . . . . . . . . . . . . . . 11

2.9 Mounting of the distributor wedges $\ldots \ldots \ldots \ldots \ldots$

2.10 Lower wedge . . . . . . . . . . . . . . . . . . . 13

2.11 Assembly of the parallel corrugated plates . . . . . . . . . . . 14

3.1 Horizontal cross sections of the corrugated parallel plates . . . . . . 15

4.1 Water distribution on the top of the plates . . . . . . . . . 20

5.1 Rivulet regime. . . . . . . . . . . . . . . . . . . . 21

5.2 Transition from the rivulet to bicontinuous regime . . . . . . . . 23

5.3 Homogeneous bicontinuous regime . . . . . . . . . . . . . . 24

5.4 Close-up of bicontinuous regime . . . . . . . . . . . . . 25

5.5 Pore throat and pore body in the bicontinuous regime . . . . . . . 26

5.6 Flooding-fronts regime . . . . . . . . . . . . . . . . . . 27

5.7 Video images of the flooding-fronts regime $\ldots \ldots \ldots \ldots$

5.8 Video images of the flooding-waves regime $\ldots \ldots \ldots \ldots$

\section{List of Tables}

3.1 Geometrical quantities of the corrugated plates . . . . . . . . 13

3.2 Physical parameters for gas-liquid flow through corrugated plates . . 16

5.1 Flow regime map . . . . . . . . . . . . . . . . . . . . . 31 


\section{Introduction}

Glows through corrugated ducts have received significant attention in the past beERIUs et al., 1999; CAVATORTA et al., 1999; FoCKE AND KNIBBE, 1986). Examples are plate heat exchangers, static mixers, regenerators, adsorbers, and catalyststo name a few. Many investigations of a theoretical and experimental nature have been conducted for single-phase flows in corrugated ducts. However, similar work for two-phase flows is lacking. In particular, the gas-liquid countercurrent flow schemewhere the gas flows upward driven by pressure drop and the liquid trickles downward driven by gravity - has been largely overlooked.

The impetus to study such a flow scheme arises from yet another example of the application of flows through corrugated ducts, that is, packing elements for chemical contactors made of corrugated sheets which are stacked vertically and made of various materials. These packings have gained acceptance as filling components of modern packed towers used in a variety of chemical separation processes - notably distillation.

Despite the omnipresence of packed towers in the industrialized world, their hydraulics remains poorly understood and prevailing flow modeling techniques have been grounded in inadequate semi-empirical models (KISTER, 1992; StICHLMAIR AND FAIR, 1999). This state of affairs leaves much room for improvement since chemical processes that employ packed towers are major sources of energy usage and waste generation. In recent years, part of the revival of interest in improving these industrially important devices stems from an increasingly stringent environmental legislation.

This research provides insight into gas-liquid counterflow mechanisms in structured packed towers by examining similar flows through a pair of transparent parallel cross corrugated plates - a similar approach was pursued by MELLI et al. (1990) when studying cocurrent downflow in a network of passages. In addition, our experimental set-up is comprised of a well-defined system amenable to modeling based on firstprinciples that should prove valuable in validating theoretical models.

This manuscript is organized as follows. Section 2 fully describes the experimental setup. Physical quantities of interest and measurement procedures are presented in sections 3 and 4, respectively. A classification of significant flow regimes observed via high-speed video is featured in section 5. They include the rivulet, bicontinuous, flooding-fronts, and flooding-waves regimes. To our knowledge, these regimes have not yet been reported in the literature. Section 6 concludes with the significance of these regimes and implications relevant to the study of flows in packed towers. 


\section{Experimental apparatus}

The experimental set-up (fig. 2.1) constructed to visualize the air-water counterflow through parallel corrugated plates consisted of three main units (with auxiliaries): a constant-level water reservoir, a sealed water distributor chamber with a pair of corrugated plates mounted at the bottom, and a water supply tank.

The constant-level water reservoir was a stainless steel vertical cylinder of $38 \mathrm{~cm}$ in length with and an internal diameter of $36 \mathrm{~cm}$ (internal volume of $39 \ell$ ). The reservoir's base was held $46 \mathrm{~cm}$ above the bottom plane of the water distributor chamber to allow the water flow from the reservoir to be driven to the chamber by gravity. Distilled water was fed to the bottom of the reservoir through two 19.1mm internal diameter tubes, while a second tube with a 27.5 -mm internal diameter, positioned $50 \mathrm{~mm}$ below the top of the container, returned the water overflow to the water supply tank. A 26-mm internal diameter tube located $35.6 \mathrm{~cm}$ below the top of the reservoir fed water to the distribution chamber at a constant flow rate which was measured with a variable area flowmeter (Omega Engineering, Inc., Stamford CT, model FL-75B, maximum capacity of $37.9 \ell / \mathrm{min}$, minimum capacity of $3.79 \ell / \mathrm{min}$, resolution of $0.75 \ell / \mathrm{min}$ ) and controlled with an angle PVC plug valve.

Two centrifugal pumps (Little Giant Pump Co., Oklahoma City, OK, model 2-MD, $3000 \mathrm{rpm}$, maximum capacity of $19 \ell / \mathrm{min}$ ) arranged in parallel fed water from the the supply tank to the constant-level reservoir through two 19.1-mm internal diameter nylon-reinforced PVC Tygon ${ }^{\circledR}$ tubes. The flow rate was controlled by throttling the flow with two ball valves to avoid flooding the constant-level reservoir. The supply tank was a plastic vertical cylinder $50.8 \mathrm{~cm}$ in length with a $58.4-\mathrm{cm}$ internal diameter (the volume was $136 l$ ) covered with a removable lid. The overflow tube from the constant-level reservoir was connected to the top of the water supply tank as well as three 34-mm internal diameter Tygon ${ }^{\circledR}$ tubes used to return the water that passed through the parallel corrugated plates.

The parallel corrugated plates and their auxiliaries consisted of a sealed distributor chamber with two parallel corrugated plates mounted at the bottom and a water collector reservoir at the foot of the plates (fig. 2.2). The corrugated plates were made of 31.75-mm-thick optical-grade acrylic square sheets with 44.7-cm-long sides (Atohaas North America Inc, Philadelphia, PA). The construction of these plates involved two basic steps. First (fig. 2.3), right-angled triangular-shaped corrugations with a 14-mm-long hypotenuse and 9.9-mm-long sides were carefully machined (the milling cutter was driven at high rotation and slow traversing speed to deliver a smooth and clear surface) on the surface of the acrylic plates parallel to their sides. Second (fig. 2.4), rectangular corrugated plates were obtained by cutting the corrugated square plates at a $45^{\circ}$ angle. The resulting plates were $27.66-\mathrm{cm} \times 35.66-\mathrm{cm}$ rectangles wherein the base of the original triangular corrugations was stretched by 


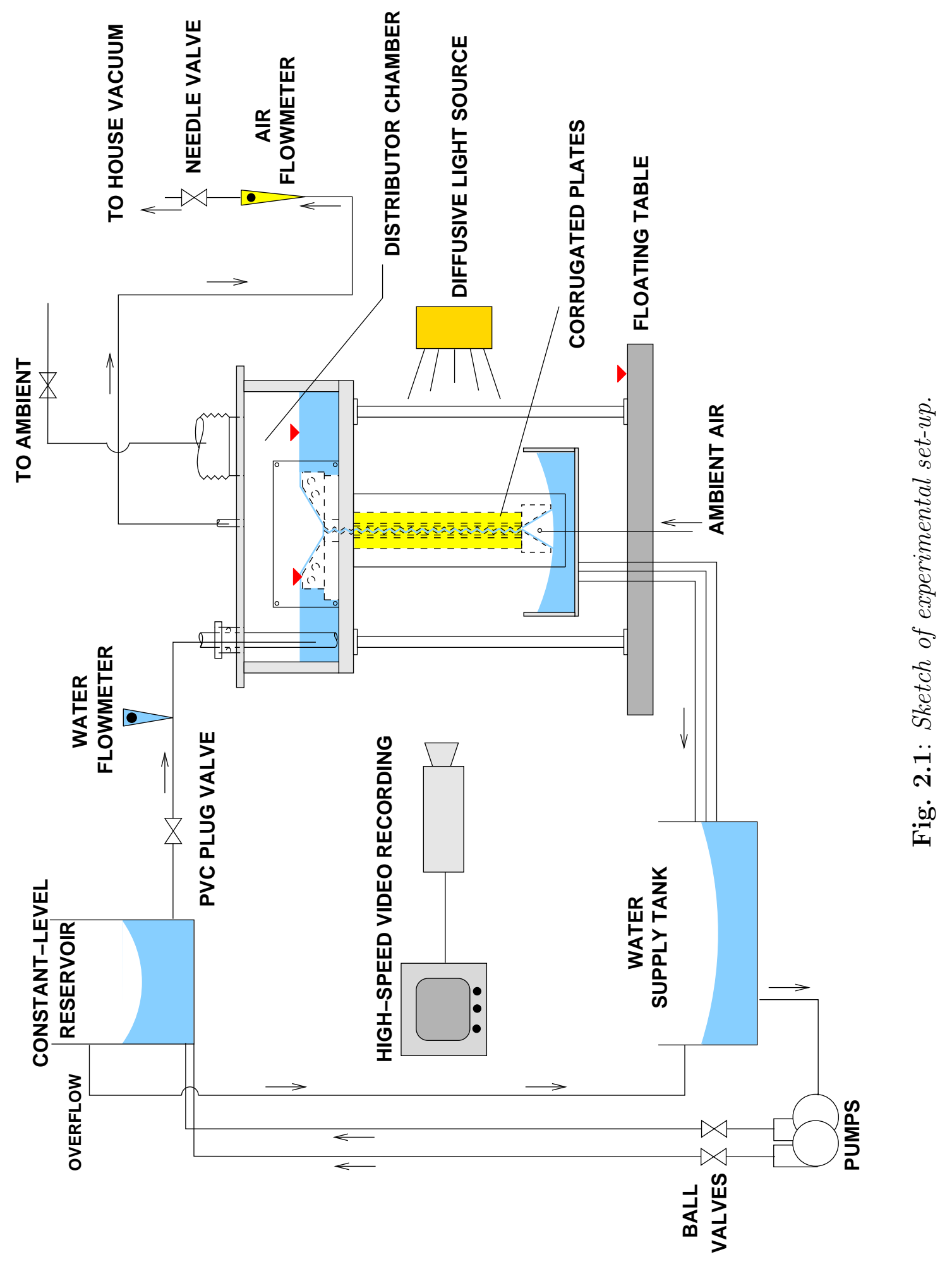

Oak Ridge National Laboratory Technical Report ORNL/TM-2000/101 pp. 1-34 
a factor of $\sqrt{2}$, while the corrugations' height remained invariant.

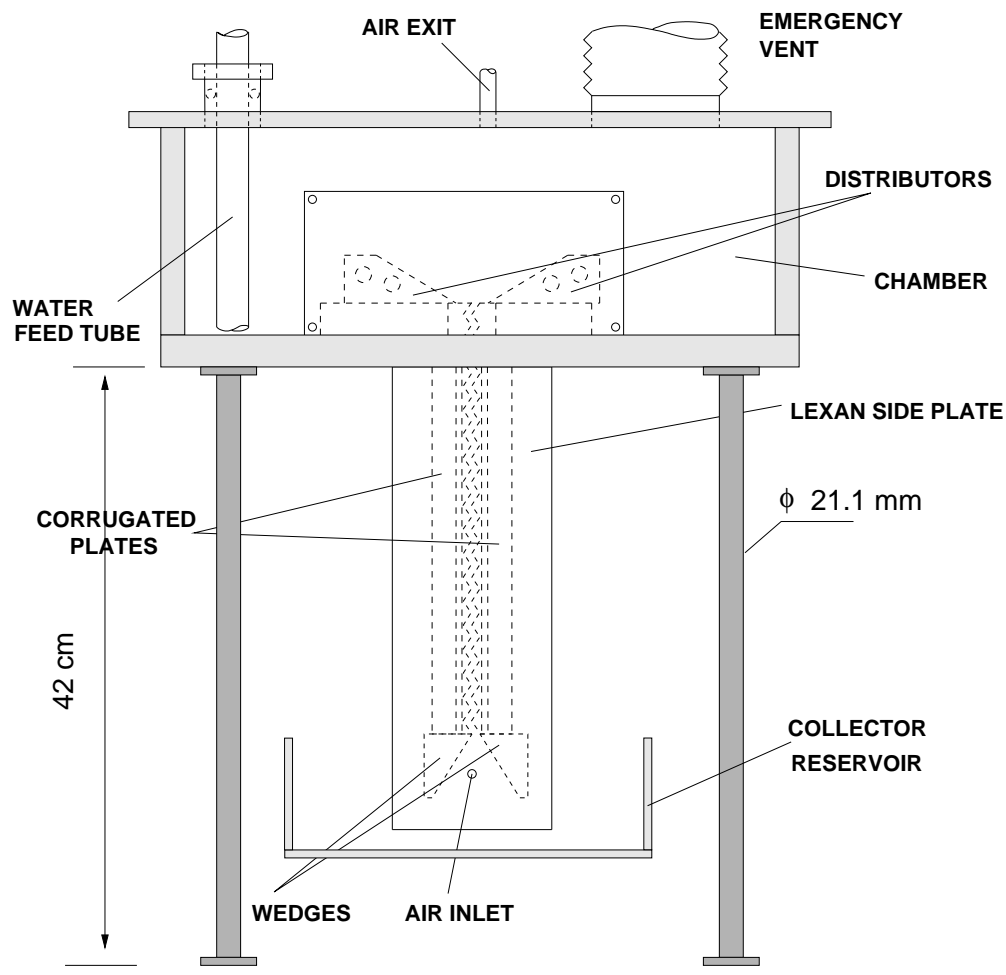

Fig. 2.2: Parallel corrugated plates set-up.

Furthermore, the plates were cut so that plate I would have troughs terminating at all four corners, while plate II would have crests incident to all of its corners. Both plates had 32 corrugations along their length and 14 corrugations along their width. Grooves were carved on the sides of the plates to accommodate a 5.4-mm rubber "O"-ring to allow the sides to be sealed by pressing polycarbonate (Lexan ${ }^{\circledR}$, General Electric Plastics, Mt. Vernon, IN) plates against them.

A ledge of $2.54 \mathrm{~cm}$ by $1.27 \mathrm{~cm}$ was cut on the top of the plates to provide support for the horizontal attachment of an additional Lexan ${ }^{\circledR}$ sheet (see shoulder support below) used to bolt the plates onto the bottom of the distribution chamber. Finally the corrugated side of the plates were polished with a cotton buffing wheel (3500 rpm) and a silicon-based compound (Kocour HF-1) to recover optical clarity. In the polishing process, the edge of the crests were smoothed with a radius of curvature of approximately $0.7 \mathrm{~mm}$. It was verified that the corrugated side of the plates was flat to the extent that when the plates were pressed, with the corrugations facing each other, all crests touched. 


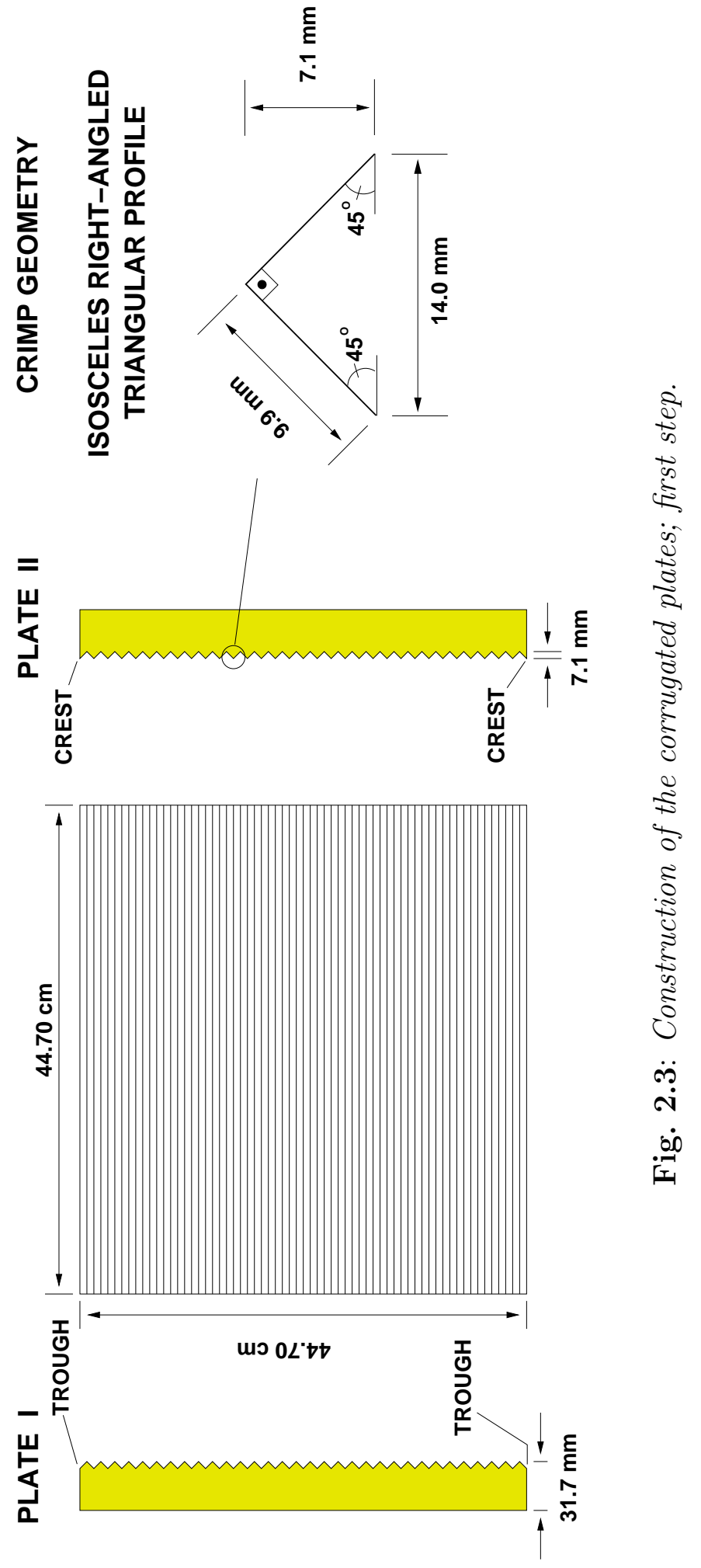




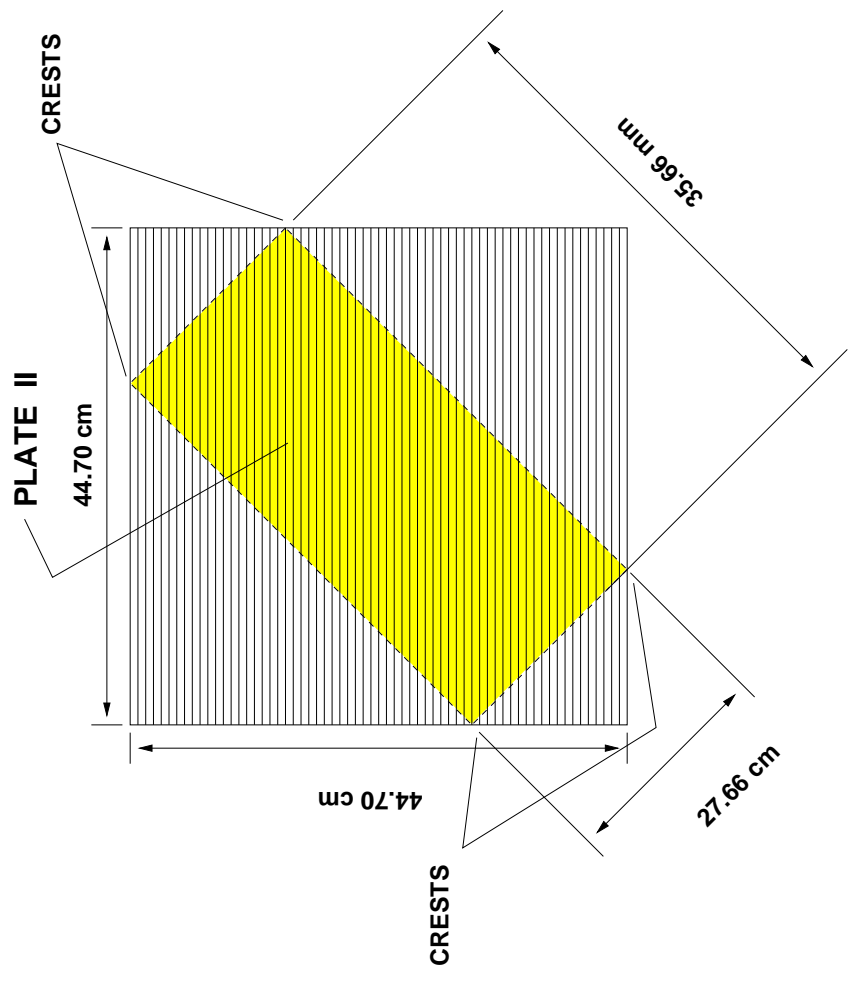

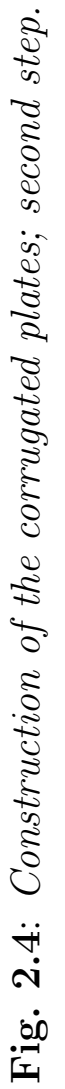

Oak Ridge National Laboratory Technical Report ORNL/TM-2000/101 pp. 1-34 
The corrugated plates were attached to the bottom of the distribution chamber by two additional "shoulder" pieces (fig. 2.5) — two 25.4-mm-thick Lexan ${ }^{\circledR}$ plates bolted to the ledge of the corrugated plates with five $6.4-\mathrm{mm}$ hex-head screws evenly spaced across the width of the plates. The 30.2-cm-long and 7.5-cm-wide shoulder piece on plate I was equipped with five countersunk $6.4-\mathrm{mm}$ hex-head bolts to fasten the piece onto the bottom of the distribution chamber. Similarly, plate II's shoulder piece was $30.2 \mathrm{~cm}$ in length and $10.8 \mathrm{~cm}$ in width, but its three countersunk bolts were free to move along the counter-drilled slots. Plate II was allowed to be positioned at variable gap lengths relative to plate I. Furthermore, the shoulder pieces extended to the sides of the plates to provide additional support and to prevent lateral inflow of water. Under the operating condition of zero gap between the plates, a 25.4-mm x 12.7$\mathrm{mm} \times \mathrm{x}$.1-mm block of closed seal foam rubber (Rubatex) was used to seal the space between the shoulder pieces (figs. 2.6 and 2.7).

Water distribution on the top of the corrugated plates was accomplished by letting the water in the distribution chamber overflow smoothly by gravity onto two wedges (fig. 2.8). The wedges were machined from blocks of poplar wood (with ill-defined grains) and sand finished for smoothness. The base of the wedges were $27.66 \mathrm{~cm}$ long; the height, $3.8 \mathrm{~cm}$; and the flat top surface, $2.5 \mathrm{~cm}$. Two 12.5 -mm-diameter stainless steel rods were inserted in two 12.5-mm-diameter holes drilled across the wedges. This prevented the wedges from warping when they were wetted and subsequently dried. After wetting, the wedges swelled and had to be recut twice at the the original $27.66 \mathrm{~cm}$ length. Hence, they were kept permanently soaked in distilled water to avoid any additional change in geometry.

The distributor wedges were mounted on top of the shoulder support (fig. 2.5) and held in place by two 25.4-mm-thick opticaly clear Lexan ${ }^{\circledR}$ plates that rested partially on the shoulder piece and partially at the bottom of the reservoir. Four threaded 6.2-mm-diameter stainless steel rods with corresponding wing nuts were used to press the Lexan ${ }^{\circledR}$ plates laterally against the shoulder pieces and the wedges (fig. 2.9). Thus, it was possible to position the sharp edge of the wedges at different distances from the corrugated plates.

The bottom of the distribution chamber consisted of a 25.4-mm-thick Lexan ${ }^{\circledR}$ square plate with an area of $400 \mathrm{~cm}^{2}$ which had a $7.62-\mathrm{cm} \times 27.66-\mathrm{cm}$ slot at the center, where the plates could be mounted on top of a 1.3-mm-thick rubber gasket. The side walls of the reservoir were 19-mm-thick acrylic plates measuring $16.5 \times 50.8 \mathrm{~cm}$ that were glued and bolted (five stainless steel socket-head 6.4-mm screws) onto the bottom plate. A soft self-adhesive weather stripping foam gasket, $6 \mathrm{~mm}$ thick, was glued on the top of the side walls so a 56 -cm x 56 -cm clear Lexan ${ }^{\circledR}$ lid could seal the reservoir with the aid of eight 30.5-cm-long Quick-Grip ${ }^{\circledR}$ bar clamps. The clamps pressed the lid against the bottom plate.

The lid had a 44.8-mm-diameter leak-proof slip nut fitting to allow the water 


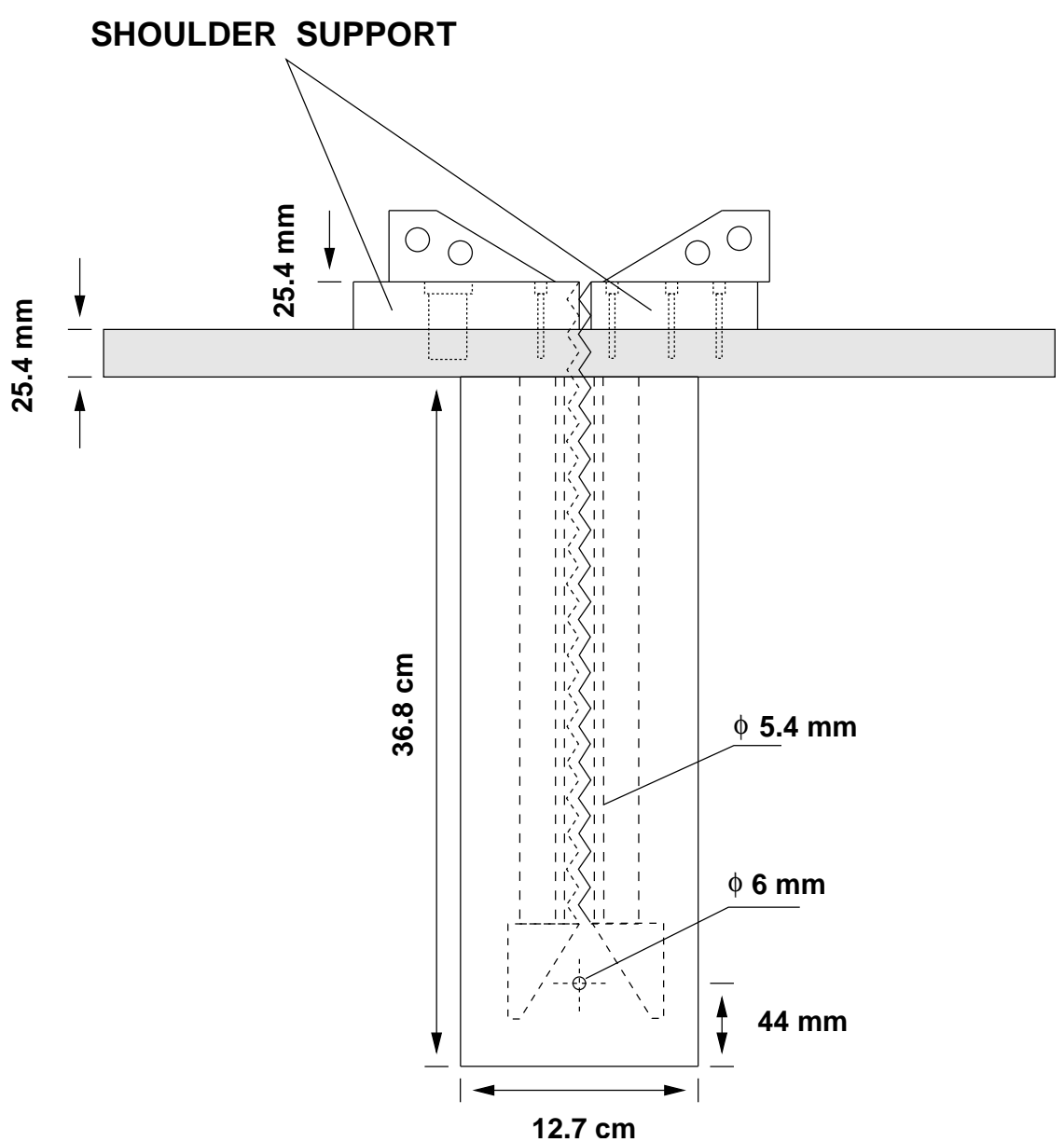

Fig. 2.5: Attachment of the corrugated plates onto the bottom of the distribution chamber via "shoulder" support pieces. 


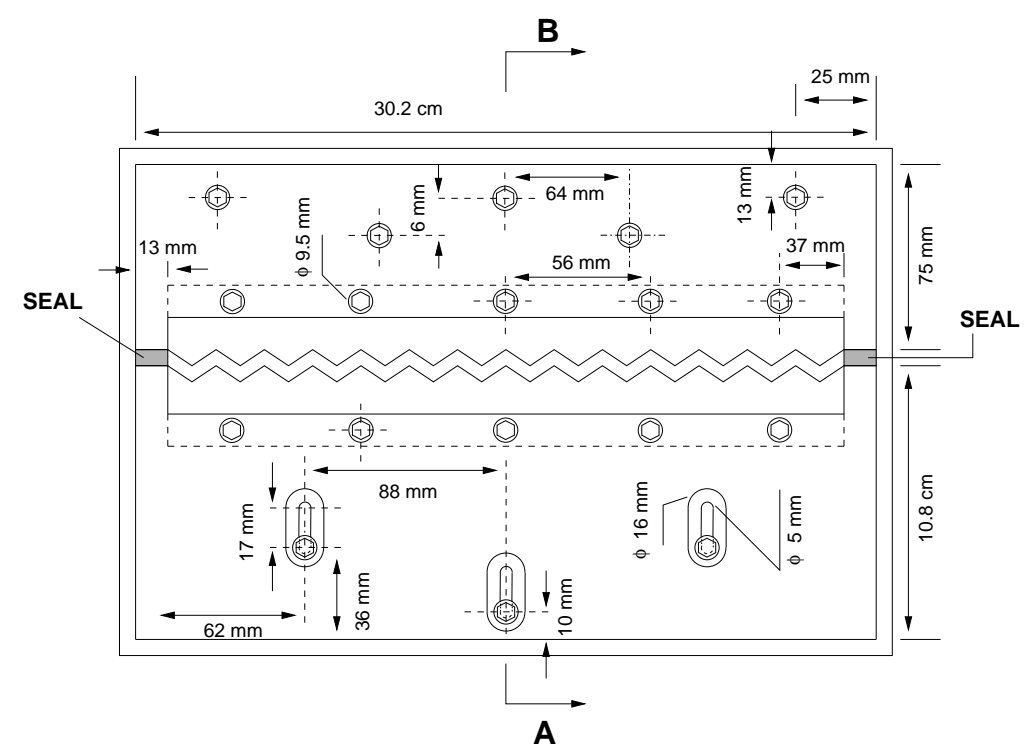

Fig. 2.6: Top view of the combined shoulder pieces and corrugated plates at zero gap position, showing the 25.4-mm $x$ 12.7- $\mathrm{mm} x$ 7.1-mm block of foam rubber used to avoid side inflow of water.

feeding tube (26-mm internal diameter) to slide and be positioned $1 \mathrm{~cm}$ above the bottom of the chamber. A 9.5-mm brass male adaptor was installed at the center of the lid to withdraw the air that had flown through the corrugated plates. The air flow rate was measured by two variable area flowmeters installed in series. The upstream flowmeter (Omega Engineering, Inc., Stamford, CT, model FL-112; maximum capacity of $2.1 \mathrm{\ell} / \mathrm{min}$; minimum capacity of $20 \mathrm{~m} \ell / \mathrm{min}$ ) measured the low-end range of air flow rates, while the downstream flowmeter (Omega Engineering, Inc., Stamford CT, model FL-114; maximum capacity of $36 \ell / \mathrm{min}$; minimum capacity of $1 \ell / \mathrm{min}$; resolution of $1 \ell / \mathrm{min}$ ) measured the high-end range. The gas flow rate was controlled by a needle valve (Whitey ${ }^{\circledR}$ SS8RF8, 21.4-mm pipe) mounted downstream of the flowmeters. Since the valve was connected to the house vacuum line, the pressure at the downstream side of the valve was approximately $450 \mathrm{~mm} \mathrm{Hg}$. The lid also had a 10.2-cm-diameter wire-reinforced corrugated hose (Flexexaust) connected to a PVC union head ball valve used for releasing the air from the chamber quickly (emergency vent in fig. 2.2).

At the foot of the plates was a $50.8-\mathrm{cm} \times 29.2-\mathrm{cm} \times 8.9-\mathrm{cm}$ collector reservoir designed to hold the water that came out through the plates. This collector also served to keep the water at a certain level to assist in creating a water-sealed chamber for feeding dry air into the parallel plates. This subject will be further elaborated on 


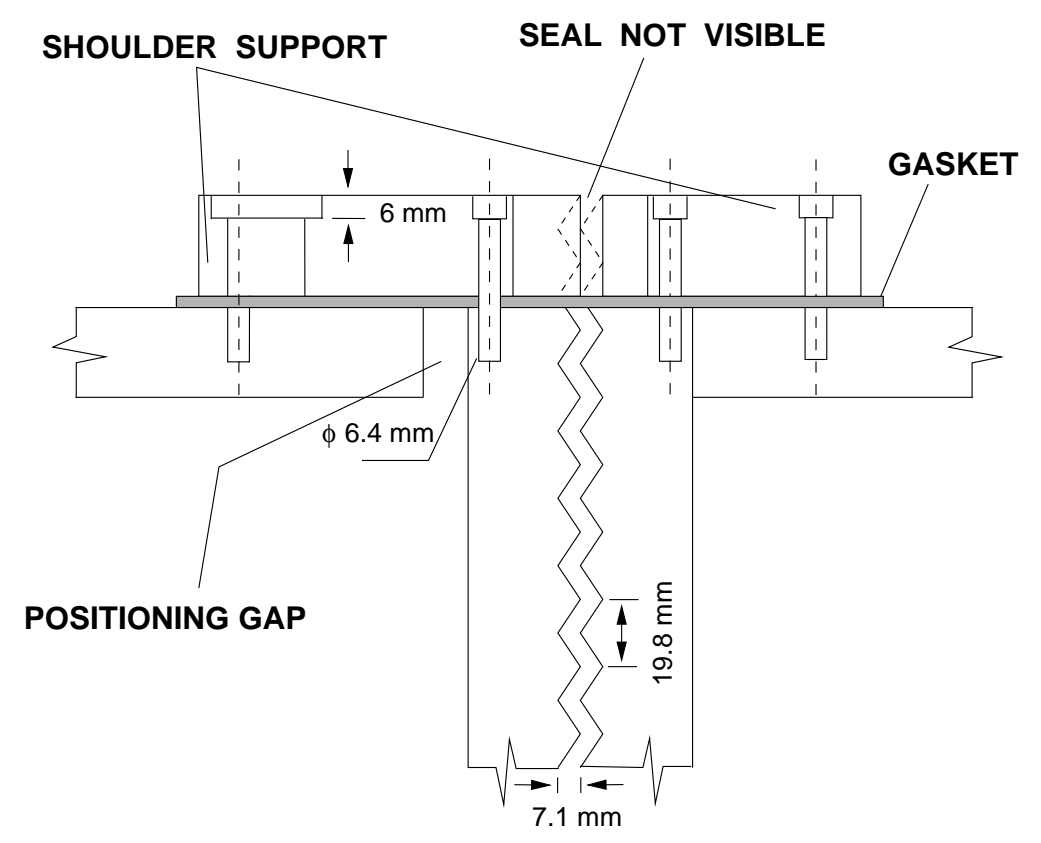

\section{A-B}

Fig. 2.7: Side view of the combined shoulder pieces and corrugated plates at zero gap position (refer to the top view in fig. 2.6). 


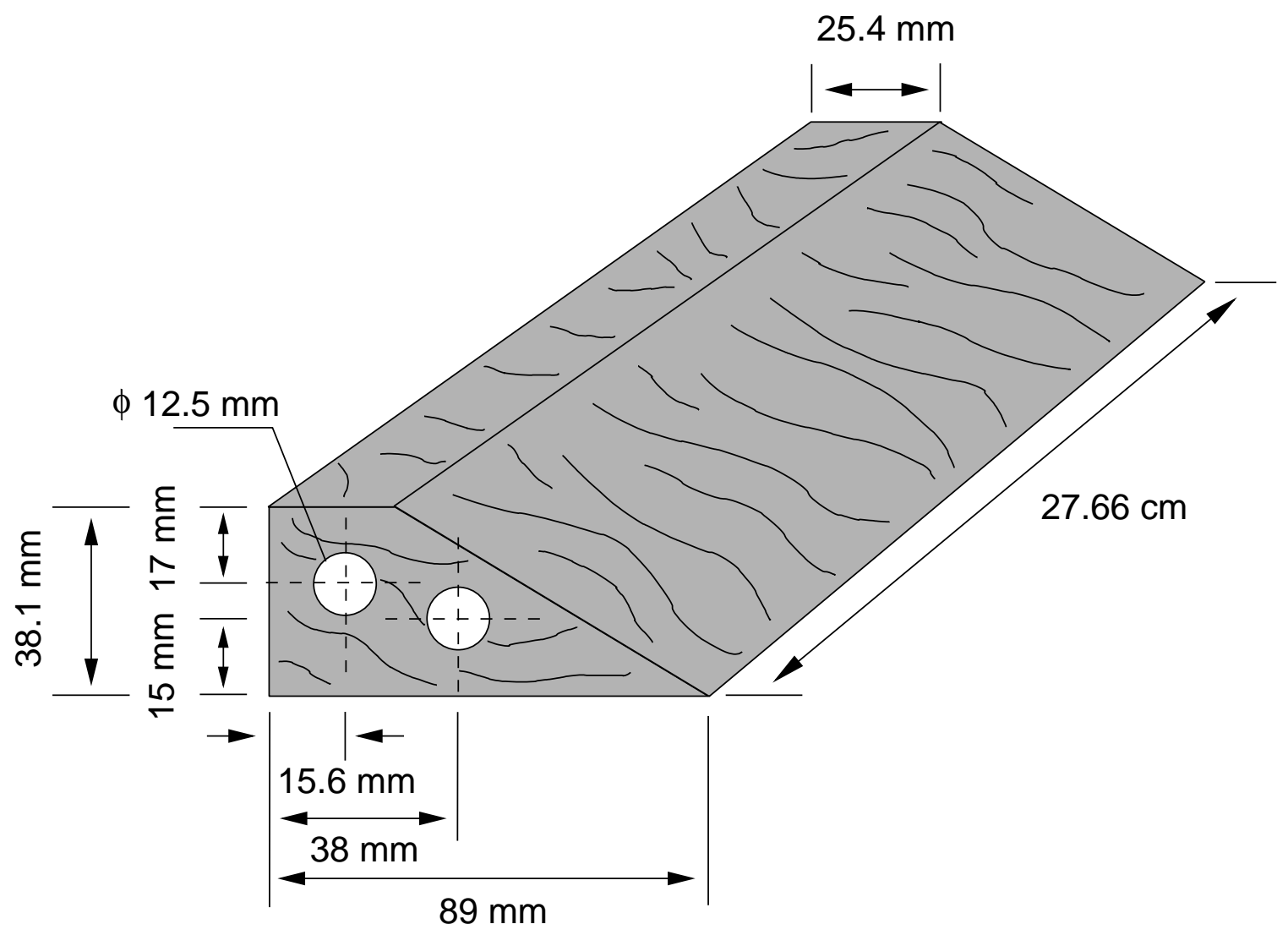

Fig. 2.8: Water distributor wedge (poplar wood).

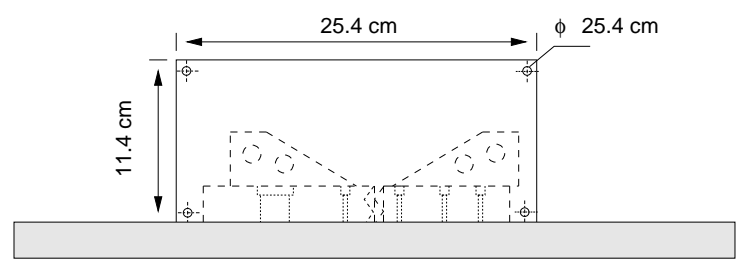

SIDE VIEW

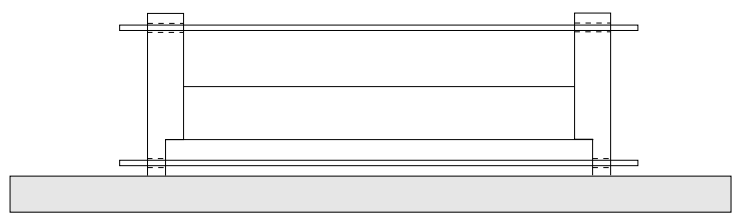

FRONT VIEW

Fig. 2.9: Mounting of the distributor wedges. 
in light of mass transfer in a forthcoming manuscript (DE AlmeIdA, 2000). Ambient air was supplied at the water outlet. Hence, controlling the water level in the collector reservoir was not a relevant issue in this study. Three Tygon ${ }^{\circledR}$ plastic tubes $(34-\mathrm{mm}$ internal diameter) were connected $43 \mathrm{~mm}$ below the top of the collector reservoir. The surplus water was conducted through these tubes to the water supply tank via gravity.

Two other wedges made of poplar wood were used to guide the water away from the corrugated plates at the water outlet. These wedges (fig. 2.10) were installed at the foot of the plates in reverse order of the distributor wedges described earlier (fig. 2.9). The lower wedges were held in place by the side clear Lexan ${ }^{\circledR}$ plates pressed against the rubber "O"-rings by means of two 30.5-cm-long Quick-Grip ${ }^{\circledR}$ clamps. The water level was kept just below the air inlet so that the wedges were partially submerged in the water.

The distributor chamber was mounted on four stainless steel rods $42 \mathrm{~cm}$ long and $21.1 \mathrm{~mm}$ in diameter. The rods were bolted onto a floating table (NRC Newport Corporation, Fountain Valley, CA) such that the chamber, wedges, and corrugated plates were leveled. Both sides of the corrugated plates were visible. A 500-Watts halogen lamp controlled through a voltage transformer Variac ${ }^{\circledR}$ (General Radio Company, Cambridge, MA) was positioned on one side of the plates. On the opposing side, a high-speed video camera (Ektapro EM Motion Analyzer, Eastman Kodak, San Diego, CA) was placed on a tripod and connected to a processor hooked to an s-video capturing board (InVideo PCI, Focus Enhancements, Wilmington, MA) installed in a personal computer (Dell OptiPlex ${ }^{\circledR}$ GX1 400 Mhz, OS Windows NT 4.0). The light of the halogen lamp was diffused by Mylar ${ }^{\circledR}$-coated paper, which was attached by velcro to the supporting steel rods.

The laboratory where the apparatus was installed had an independent central airconditioning system for controlling the ambient temperature and air humidity. A side view of the final assembly is shown in figure 2.11(a), while a front view is presented in figure 2.11(b).

\section{Geometrical quantities, characteristic units, di- mensionless parameters and industrial measures}

Table 3.1 provides various geometrical characteristics of the corrugated plates and the space between them that are relevant to flow analysis. Note that the cross-sectional area available for the air and water to flow, at any elevation along the plates, is constant (fig. 3.1) and so is the cross-sectional perimeter. However, two different topologies are present - one case with genus equal to zero and another with genus of 15 .

Oak Ridge National Laboratory Technical Report ORNL/TM-2000/101 pp. 1-34 


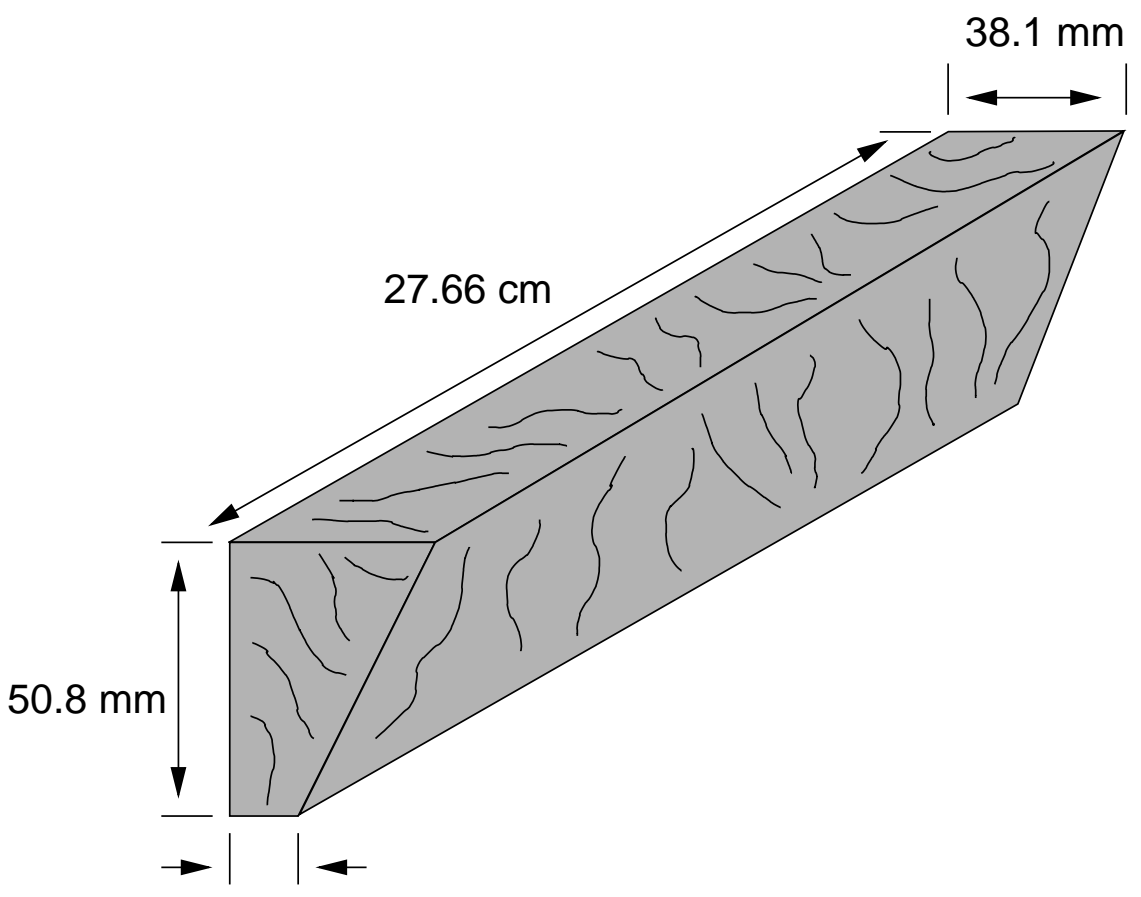

$12.7 \mathrm{~mm}$

Fig. 2.10: Lower wedge (poplar wood).

Table 3.1: Geometrical quantities of the parallel corrugated plates. Figure 2.3 contains the crimp geometry.

\begin{tabular}{|clll|}
\hline \multicolumn{5}{|c|}{ Geometrical quantities } \\
\hline \hline$a$ & cross-sectional area & 19.67 & $\mathrm{~cm}^{2}$ \\
$b$ & cross-sectional perimeter & 71.00 & $\mathrm{~cm}$ \\
$L$ & height of plates & 35.66 & $\mathrm{~cm}$ \\
$V=a L$ & void space between plates & 701.4 & $\mathrm{~cm}^{3}$ \\
$A=b L$ & total surface area & 2531 & $\mathrm{~cm}^{2}$ \\
$\epsilon$ & void fraction & 1 & \\
$A_{v}:=b L / V$ & specific surface area & 360.9 & $\mathrm{~m}^{-1}$ \\
$h:=a / b=V / A$ & hydraulic radius & 0.28 & $\mathrm{~cm}$ \\
\hline
\end{tabular}




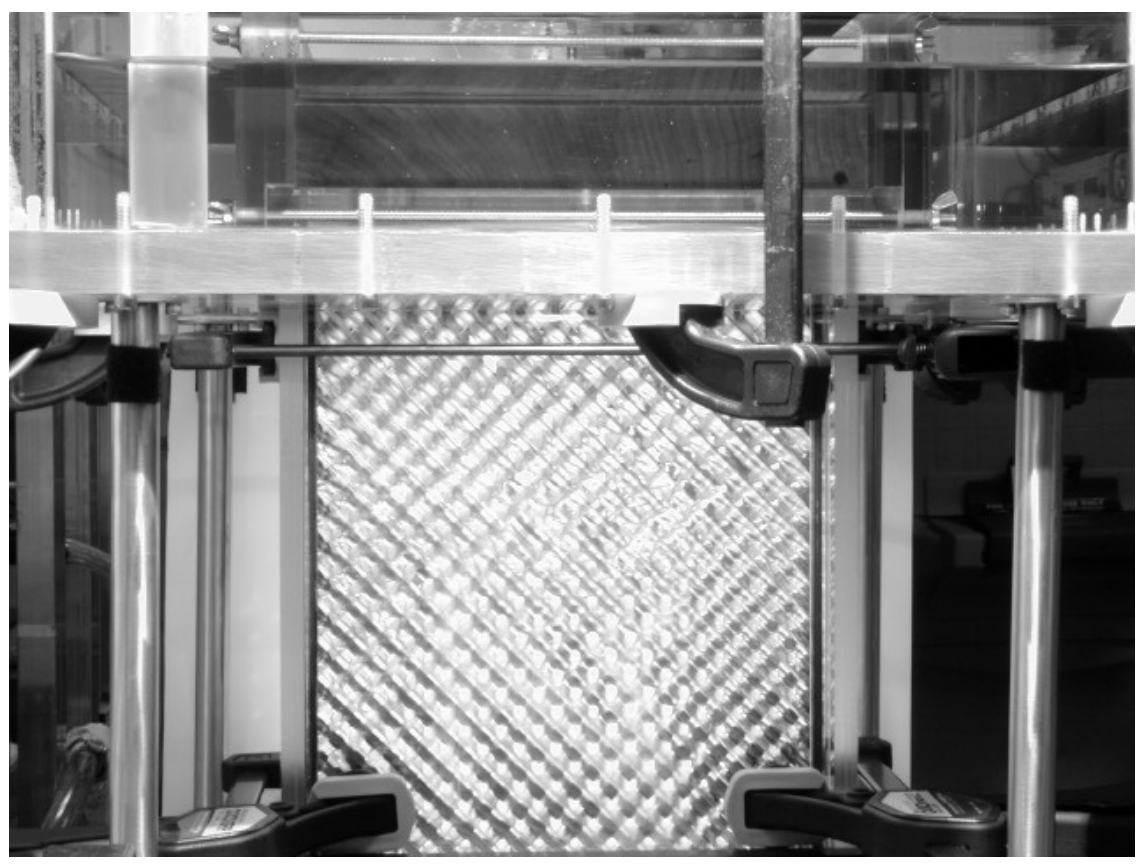

(a)

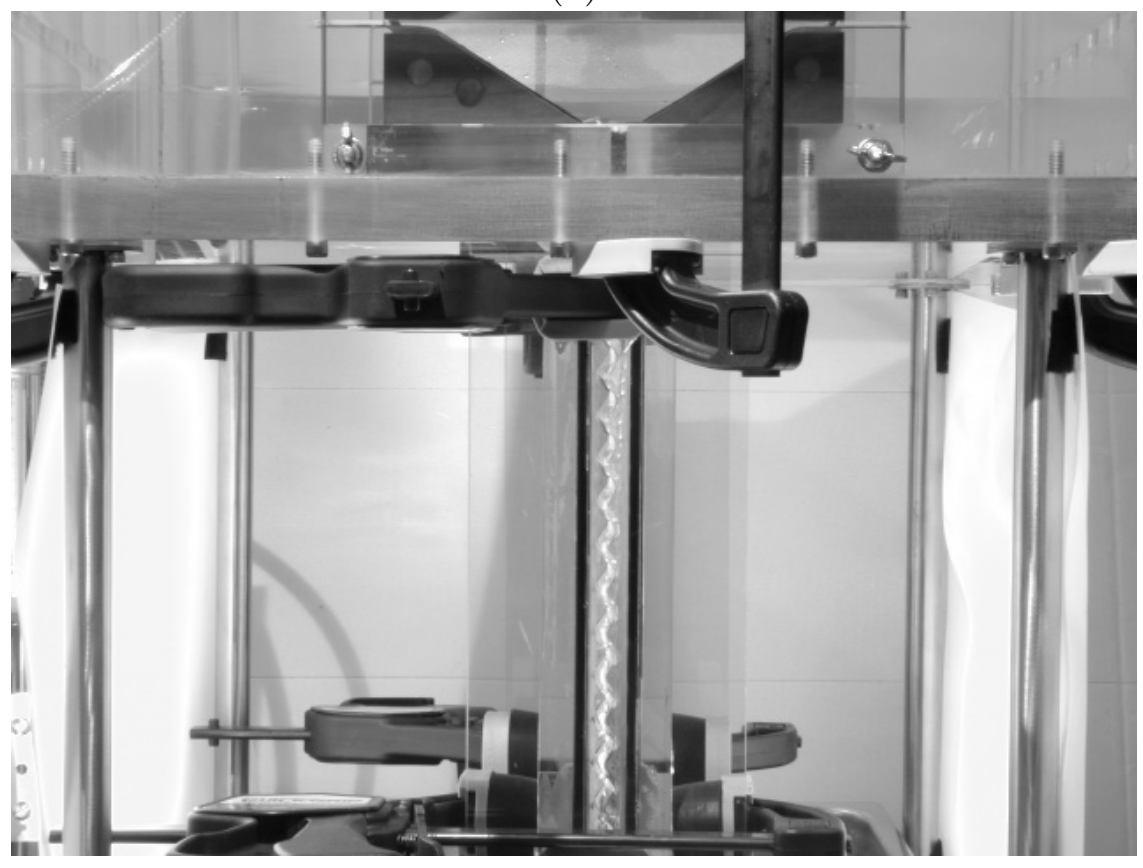

(b)

Fig. 2.11: Assembly of the parallel corrugated plates. (a) Front view. (b) Side view. 

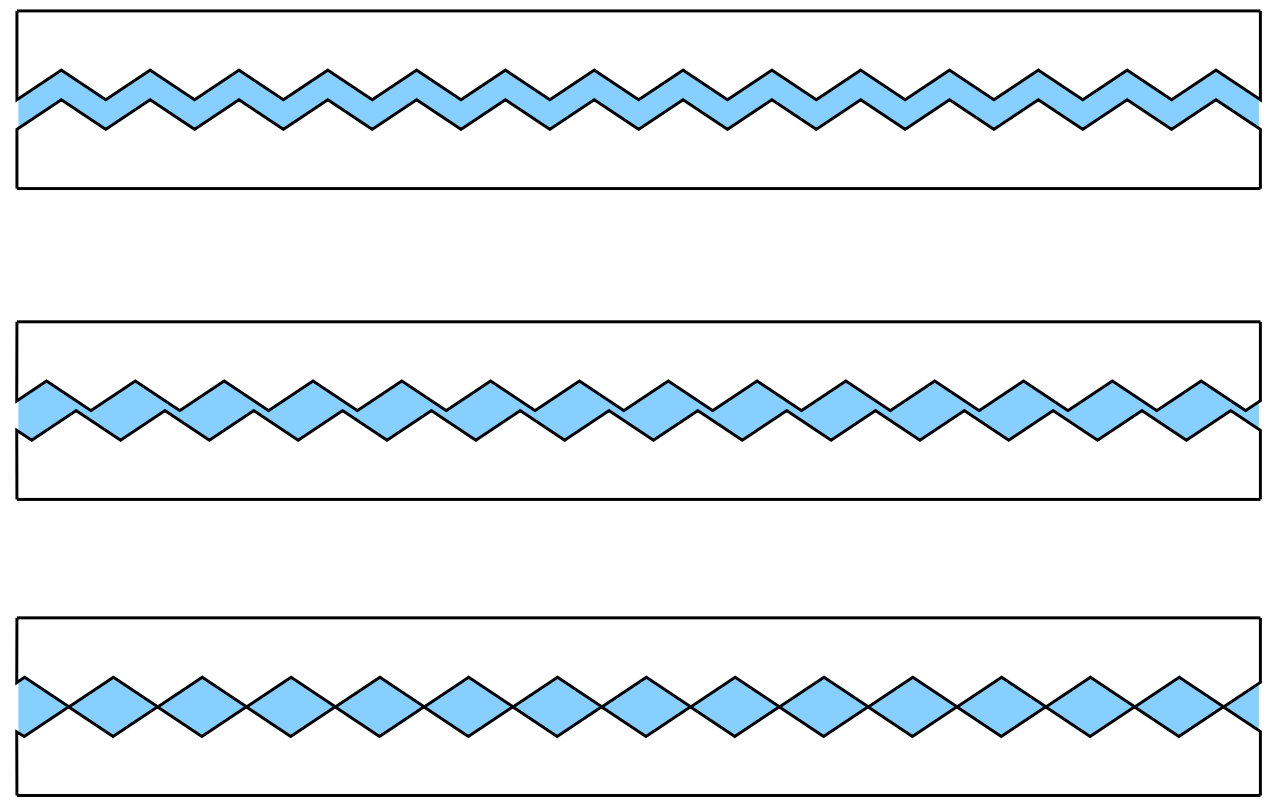

Fig. 3.1: Horizontal cross sections of the corrugated plates at three different elevations.

In addition to the geometrical quantities of the corrugated plates, a minimum of eight physical quantities are present in general gas-liquid systems (those are physical properties and flow rates; see table 3.2). Other physical and geometrical quantities of interest not listed in the tables are associated with the wetting of the plates.

A dimensional analysis of the Navier-Stokes equations for gas and liquid phases (DE AlmeidA, 1995) shows that a minimum of six independent dimensionless groups 
Table 3.2: Physical parameters for gas-liquid flow through corrugated plates ( $\mathrm{L}, \mathrm{M}$, and $\mathrm{T}$ represent units of length, mass, and time, respectively).

\begin{tabular}{|c|cll|}
\hline \multicolumn{3}{|c|}{ Physical Parameter } & $\mathrm{Unit}$ \\
\hline \hline 1 & $Q^{\ell}$ & liquid volumetric flow rate & {$\left[\mathrm{L}^{3} \mathrm{~T}^{-1}\right]$} \\
2 & $Q^{g}$ & gas volumetric flow rate & {$\left[\mathrm{L}^{3} \mathrm{~T}^{-1}\right]$} \\
3 & $\rho^{\ell}$ & liquid mass density & {$\left[\mathrm{ML}^{-3}\right]$} \\
4 & $\rho^{g}$ & gas mass density & {$\left[\mathrm{ML}^{-3}\right]$} \\
5 & $\mu^{\ell}$ & liquid dynamic viscosity & {$\left[\mathrm{ML}^{-1} \mathrm{~T}^{-1}\right]$} \\
6 & $\mu^{g}$ & gas dynamic viscosity & {$\left[\mathrm{ML}^{-1} \mathrm{~T}^{-1}\right]$} \\
7 & $\sigma$ & surface tension coefficient & {$\left[\mathrm{MT}^{-2}\right]$} \\
8 & $g$ & gravity acceleration & {$\left[\mathrm{LT}^{-2}\right]$} \\
\hline
\end{tabular}

are involved in dynamically similar flow states for the system, namely,

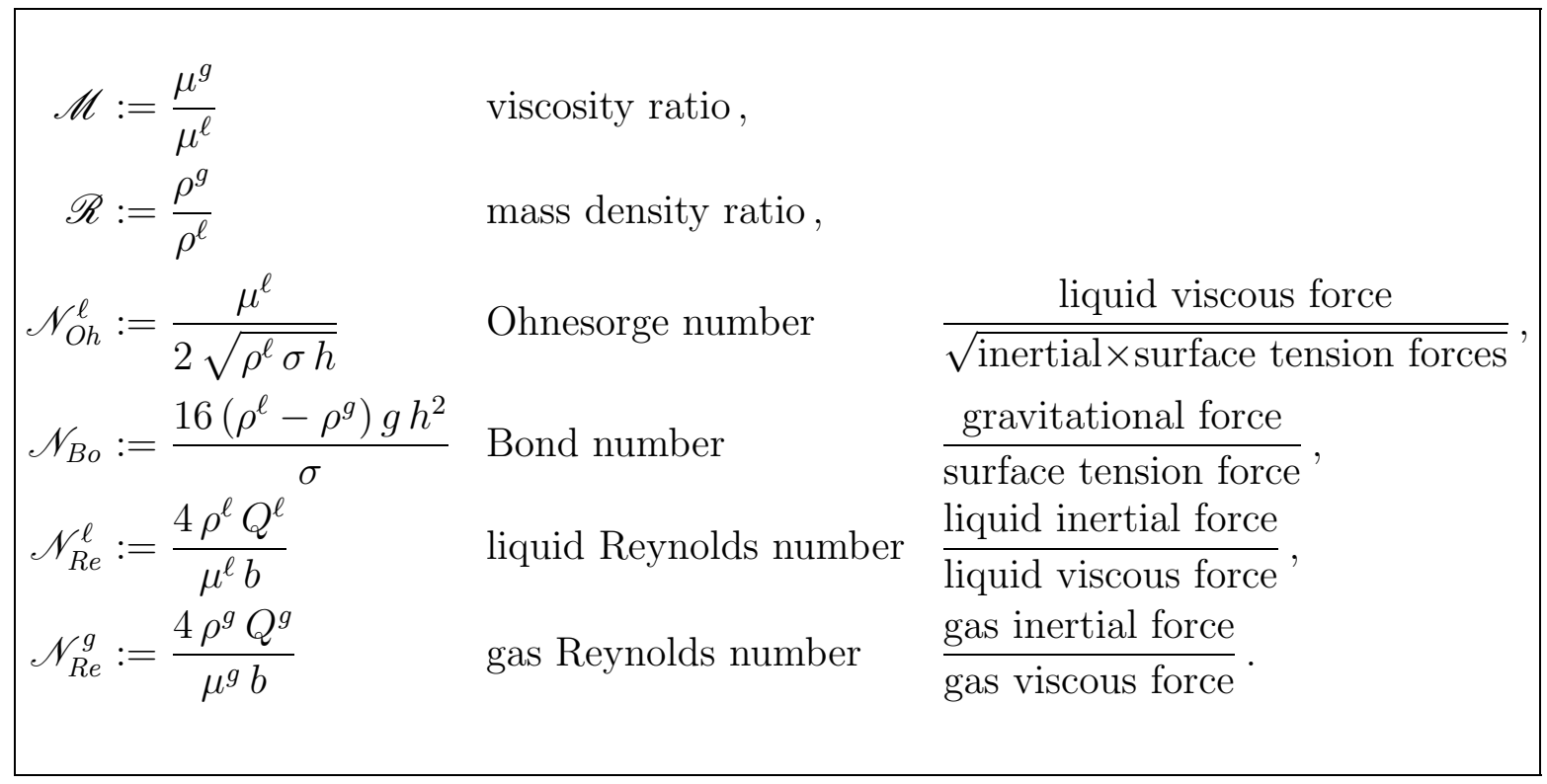

Alternatively, the Reynolds numbers can be expressed in terms of the mean fluid velocities, $\bar{v}^{g}$ and $\bar{v}^{\ell}$, of each phase, and the hydraulic radius

$$
\mathscr{N}_{R e}^{\alpha}=\frac{4 \rho^{\alpha} \bar{v}^{\alpha} h}{\mu^{\alpha}} \quad \text { where } \quad \bar{v}^{\alpha}:=\frac{Q^{\alpha}}{h b} \quad \text { for } \quad \alpha=g, \ell
$$


Furthermore, other dimensionless groups can be derived from the ones listed above. Since the Ohnesorge and Bond numbers appear only in the interfacial momentum balance, dividing this equation by the Bond number allows for the substitution of the Ohnesorge number by the Stokes group, $\mathscr{N}_{S t}^{\ell}:=\frac{\left(\mathscr{N}_{O h}^{\ell}\right)^{2} \mathscr{N}_{R e}^{\ell}}{\mathscr{N}_{B o}}=\frac{\mu^{\ell} Q^{\ell}}{16\left(\rho^{\ell}-\rho^{g}\right) g b h^{3}}$. Similarly, since the square of the Ohnesorge number enters the interfacial momentum balance multiplied by $\mathscr{N}_{R e}^{\ell}$, the capillary number, $\mathscr{N}_{C a}^{\ell}$, can replace $\mathscr{N}_{O h}^{\ell}$, through the definition $\mathscr{N}_{C a}^{\ell}:=\left(\mathscr{N}_{O h}^{\ell}\right)^{2} \mathscr{N}_{R e}^{\ell}=\frac{\mu^{\ell} Q^{\ell}}{\sigma b h}$.

In an attempt to relate the measurements obtained in this work to data commonly found in brochures of packing suppliers, we list a few quantities in wide use in the chemical industry. We only need to define quantities associated with the socalled pressure drop capacity curves. The data is organized in a family of curves, parametrized by the liquid load, $u^{\ell}$ (also termed liquid superficial velocity), typically reported in $\mathrm{m} / \mathrm{h}$ (or US gpm/ $\mathrm{ft}^{2}$ ), with the abscissa representing the gas flow factor $F$ and the ordinate representing the pressure drop in the gas phase between the outflow and inflow of a packed tower. The superficial velocity of phase $\alpha=\ell, g$ is defined as the mean velocity of the phase, based on the volumetric flow rate and the cross-sectional area of the tower. Hence, the corresponding quantity here is

$$
u^{\alpha}=\frac{Q^{\alpha}}{a} \quad \text { for } \quad \alpha=g, \ell .
$$

The gas flow factor, which is proportional to the square root of the gas kinetic energy, is defined in terms of the gas load or gas superficial velocity $u^{g}$ as

$$
F=u^{g} \sqrt{\rho^{g}}
$$

and is often measured in $\mathrm{m} / \mathrm{s}\left(\mathrm{kg} / \mathrm{m}^{3}\right)^{1 / 2}\left(\mathrm{or} \mathrm{ft} / \mathrm{s}\left(\mathrm{lb} / \mathrm{ft}^{3}\right)^{1 / 2}\right)$. Note that $u^{\alpha}$ and $F$ are "local" analogues of similar quantities used at the tower scale.

\section{Measurements and procedures}

Only the volumetric flow rates of the gas and the liquid phases, $Q^{g}$ and $Q^{\ell}$, were varied in this investigation. All measurements were obtained at the room temperature of approximately $23^{\circ} \mathrm{C}$; therefore, the following tabulated values at the ambient pressure of $750 \mathrm{~mm} \mathrm{Hg}$ and air relative humidity of $30 \%$ for the physical properties in table 3.2 were assumed: $\rho^{\ell}=1.0 \times 10^{3} \mathrm{~kg} / \mathrm{m}^{3}$, air density $\rho^{g}=1.0 \mathrm{~kg} / \mathrm{m}^{3}$, water dynamic viscosity $\mu^{\ell}=1.0 \times 10^{-3} \mathrm{~kg} / \mathrm{m}$-s, air dynamic viscosity $\mu^{g}=1.8 \times 10^{-5} \mathrm{~kg} / \mathrm{m}-\mathrm{s}$, and air-water surface tension $\sigma=6.5 \times 10^{-2} \mathrm{~kg} / \mathrm{s}^{2}$. Accordingly, only two dimensionless groups varied, namely, the liquid and gas Reynolds numbers, $\mathscr{N}_{R e}^{\ell}$ and $\mathscr{N}_{R e}^{g}$. The remaining groups assumed constant values: $\mathscr{M}=\frac{1}{50}, \mathscr{R}=\frac{1}{1000}, \mathscr{N}_{O h}^{\ell}=1.2 \times 10^{-3}$, and $\mathscr{N}_{B o}=19$. 
The acrylic corrugated plates were carefully cleaned with a mild detergent commonly used on laboratory glassware and rinsed with distilled water. The plates were then attached to the bottom of the distribution chamber. Distilled water contained in the supply tank was circulated in the system. Every reasonable effort was made to keep the circulating water clean by periodically emptying the system and filling it with unused water, and by covering the supply tank and the constant-level reservoir to avoid contact of the water with the ambient air.

Before each run at a fixed value of the liquid flow rate, the void space between the plates was initially fully flooded with water to allow complete wetting of the corrugated surface. This was accomplished by running both water pumps at full capacity and supplying the distributor chamber with maximum liquid volumetric flow rate $(38 \ell / \mathrm{min})$. The chamber was kept at almost house vacuum level $(450 \mathrm{~mm} \mathrm{Hg})$, up to the point of complete flooding. After waiting for the chamber to be half-filled with water, the valve connected to the emergency vent was opened at once. The layer of water built in the distribution chamber was enough to flood the void space between the plates and to establish a single phase flow for a few seconds.

The volumetric flow rate of the pumps was adjusted by throttling the ball valves, whereas the desired water flow rate fed to the distribution chamber was set by controlling the plug valve (fig. 2.1). A systematic observation of flow regimes was performed for the following selected values of liquid volumetric flow rates measured in $\ell / \mathrm{min}$ :

$$
Q^{\ell}=1.9,3.8,6.1,7.6,9.8,11.4,13.6,
$$

with corresponding values of liquid Reynolds number

$$
\mathscr{N}_{R e}^{\ell}=170,350,560,710,920,1070,1280 \text {, and }
$$

liquid load measured in $\mathrm{m}^{3} / \mathrm{h}-\mathrm{m}^{2}$ (rounded values)

$$
u^{\ell}=58,110,180,230,290,340,410 .
$$

For each value of the above liquid Reynolds number, the gas volumetric counterflow rate, $Q^{g}$ in $\ell / \mathrm{min}$, was raised discretely as follows:

$$
\begin{array}{r}
Q^{g}=0.1,0.2,0.5,1.0,1.5,2.0,4.0,6.0,8.0,10.0,12.0,14.0,16.0,18.0, \\
20.0,22.0,24.0,26.0,29.0,32.0,35.0,37.0,39.0,
\end{array}
$$

where the equivalent gas Reynolds numbers were

$$
\begin{aligned}
\mathscr{N}_{R e}^{g}=2,4,10,20,30,40, & 79,110,150,190,230,270,310,350, \\
& 390,430,470,510,570,630,690,720,760, \text { and }
\end{aligned}
$$


the gas loads, measured in $\mathrm{m}^{3} / \mathrm{s}-\mathrm{m}^{2}$ (rounded values), were

$$
\begin{gathered}
u^{g}=8.310^{-4}, 1.710^{-3}, 4.210^{-3}, 8.310^{-3}, 1.310^{-2}, 1.710^{-2}, 3.410^{-2}, 5.110^{-2} \\
6.810^{-2}, 8.410^{-2}, 1.010^{-1}, 1.210^{-1}, 1.410^{-1}, 1.510^{-1}, 1.710^{-1}, 1.910^{-1} \\
2.010^{-1}, 2.210^{-1}, 2.510^{-1}, 2.710^{-1}, 3.010^{-1}, 3.110^{-1}, 3.310^{-1} .
\end{gathered}
$$

Finally, given (3.1), the corresponding values of gas flow factor $F$ in $\mathrm{m} / \mathrm{s}\left(\mathrm{kg} / \mathrm{m}^{3}\right)^{1 / 2}$ were numerically identical to the gas load (gas superficial velocity) since $\rho^{g}=1.0 \mathrm{~kg} / \mathrm{m}^{3}$.

Not all combinations of liquid flow rates and gas flow rates were realized because of fully developed flooding. In particular at relatively high liquid flow rates, only regimes at relatively low gas flow rates were visualized. At each possible combination of flow rates, the flow regime was directly observed with the aid of a high-speed video camera equipped with various lenses (Nikon, 35-mm, 50-mm, and 70-mm lens). The time-dependent flow regimes were then digitally recorded at different recording rates which varied from 100 frames per second up to 250 frames per second, depending upon the time scale of the significant phenomena present on each particular flow regime. The total elapsed time for one recording session was set by the high-speed video camera to a maximum limit of 820 frames for any given recording frame rate. Visualizations were made on both sides of the parallel plates to verify the symmetry of the flow regime when that was the case. By exploring multiple lens sizes and image magnifications, details of the flow mechanisms at the scales of one, several, and many corrugation cell lengths could be clearly observed.

The water distribution on the top of the corrugated plates was excellent. The porous surface of the wood distributor was well wetted by water and delivered a thin, smooth, and uniform layer of liquid onto the plates for all values of liquid and gas flow rates tested (fig. 4.1).

\section{Flow regimes}

Four distinct flow regimes were discovered and featured, namely,

1. rivulet,

2. bicontinuous,

3. flooding fronts, and

4. flooding waves.

These are described in detail next.

Oak Ridge National Laboratory Technical Report ORNL/TM-2000/101 pp. 1-34 


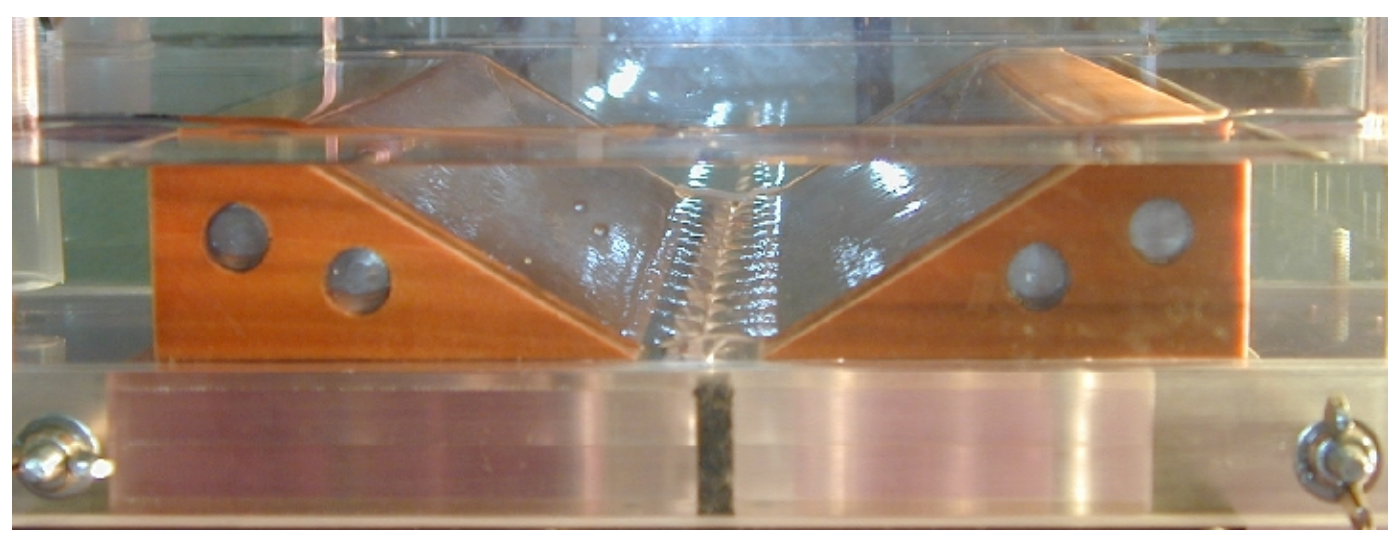

Fig. 4.1: Liquid distribution on the top of the corrugated plates exhibiting a smooth, thin, and uniform layer of water.

\subsection{Rivulet regime}

This three-phase regime is characterized by the presence of liquid rivulets (liquid discontinuous) in the majority of the corrugations' troughs on both plates. The gas phase is in continuous contact with the liquid and the exposed dry patches of the solid surface. The regime persists at all values of liquid Reynolds number $170 \leq$ $\mathscr{N}_{R e}^{\ell} \leq 350\left(58 \leq u^{l} \leq 110 \mathrm{~m} / \mathrm{h}\right)$ and all gas Reynolds numbers $\mathscr{N}_{R e}^{g} \leq 1270(F \leq$ $\left.0.33 \mathrm{~m} / \mathrm{s}\left(\mathrm{kg} / \mathrm{m}^{3}\right)^{1 / 2}\right)$. This range of liquid load, $u^{l}$, is often found in packed towers filled with structured packing of similar specific surface area. The rivulets flow along the troughs of each corrugated plate almost without any cross interaction until they reach the boundary sides of the plates, whereupon the flow interacts with an incoming rivulet from the opposite plate. At the boundaries the streams mix and are reflected back into the void space. The crests of the corrugations are dry, as well as a large fraction of the crimps' side area exposed to the gas phase.

Stationary liquid drops occupy almost all the crests' contact points. The drops do not interact visibly with the flowing rivulets, except for cases where the width of the rivulets is wide enough to reach the crimp's edge. However, since the drops survive almost indefinitely in time at all gas flow rates, a concealed mechanism should replenish the water lost by evaporation.

For the most part, the rivulets are rectilinear streams attached to the valley of the corrugations. As they grow wider by virtue of a higher liquid flow rate, they show signs of tortuosity (fig. 5.1). 


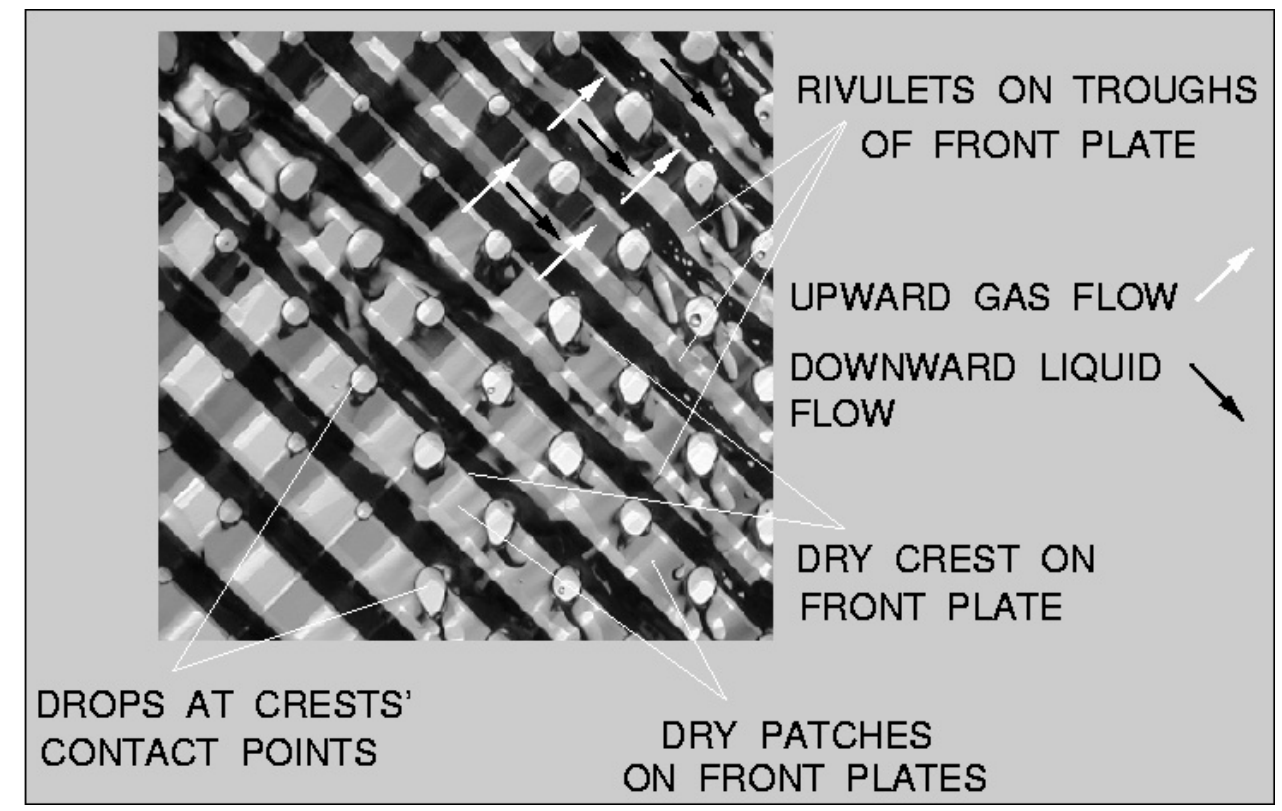

Fig. 5.1: Rivulet regime persists at values of liquid Reynolds number $170 \leq \mathscr{N}_{\text {Re }}^{\ell} \leq$ 350 (liquid superficial velocity of $58 \leq u^{l} \leq 110 \mathrm{~m} / \mathrm{h}$ ) and gas Reynolds numbers $\mathscr{N}_{R e}^{g} \leq 1270$ (gas flow factor $F \leq 0.33 \mathrm{~m} / \mathrm{s}\left(\mathrm{kg} / \mathrm{m}^{3}\right)^{1 / 2}$ ). 


\subsection{Transition from rivulet to bicontinuous regime}

At a higher liquid Reynolds number, $\mathscr{N}_{R e}^{\ell}=560\left(u^{l}=180 \mathrm{~m} / \mathrm{h}\right)$, a transition to a film-dominated regime termed bicontinuous regime (see next section) appears in the range of a gas Reynolds number of $\mathscr{N}_{R e}^{g} \leq 40\left(F \leq 1.710^{-2} \mathrm{~m} / \mathrm{s}\left(\mathrm{kg} / \mathrm{m}^{3}\right)^{1 / 2}\right)$. The transition shows one connected region where the flow is predominant in the rivulet regime and a complementary region where the flow is in the bicontinuous regime. As shown in figure 5.2, the higher liquid flow rate causes some of the rivulets to merge and flow as a film.

Typically this transition is observed at the side walls of the plates, and it has its origin at the top of the plates along the horizontal area at the forefront of the distributors' edge. The continuous liquid film wets both plates, giving rise to a network of passages whose topology is equivalent to that of the underlying crossstacked corrugated plates. At the passages' wall, the liquid film flows downward while the passages' core remains occupied by the gas phase. Upon a careful examination of the shape of the passages, it can be concluded that the network is made of a collection of pore bodies and pore throats where the cross-sectional area smoothly increases and decreases along the barycenter line of a corrugation. The passages are effectively a set of convergent-divergent connected ducts; we elaborate on this point in the next section.

It is conjectured that the gas phase in the bicontinuous region (right side of fig. 5.2) is dragged downward by the liquid because the path of lower resistance for the gas to flow is through the rivulet region. Therefore, it is likely that the gas-liquid flow in the bicontinuous region is cocurrent downward. In that case, the bicontinuous region can be regarded as one kind of maldistribution, namely, channeling of the rivulet regime, and, consequently, is detrimental to the performance of a gas-liquid contactor.

\subsection{Bicontinuous regime}

The bicontinuous regime is characterized by a homogeneous bicontinuous region throughout the plates; both the gas and liquid phases are continuous in the system. A complete transition to the bicontinuous regime takes place at liquid Reynolds number $\mathscr{N}_{R e}^{\ell}=560\left(u^{l}=180 \mathrm{~m} / \mathrm{h}\right)$ and gas Reynolds number in the range $79 \leq \mathscr{N}_{R e}^{g} \leq 350$ $\left(3.410^{-2} \leq F \leq 1.510^{-1} \mathrm{~m} / \mathrm{s}\left(\mathrm{kg} / \mathrm{m}^{3}\right)^{1 / 2}\right)$. This regime persists at higher liquid flow rates up to $\mathscr{N}_{R e}^{\ell}=710\left(u^{l}=230 \mathrm{~m} / \mathrm{h}\right)$ for lower gas flow rates in the range $\mathscr{N}_{R e}^{g} \leq 20$ $\left(F \leq 8.310^{-3} \mathrm{~m} / \mathrm{s}\left(\mathrm{kg} / \mathrm{m}^{3}\right)^{1 / 2}\right)$. This range of liquid load, $u^{l}$, is generally used on packed towers that operate under high-liquid-flow services. This operation is plagued with poor performance, ill-understood phenomena, and is notorious for numerous cases of failure.

In the bicontinuous regime, the gas flows upward, driven by the pressure gradient 


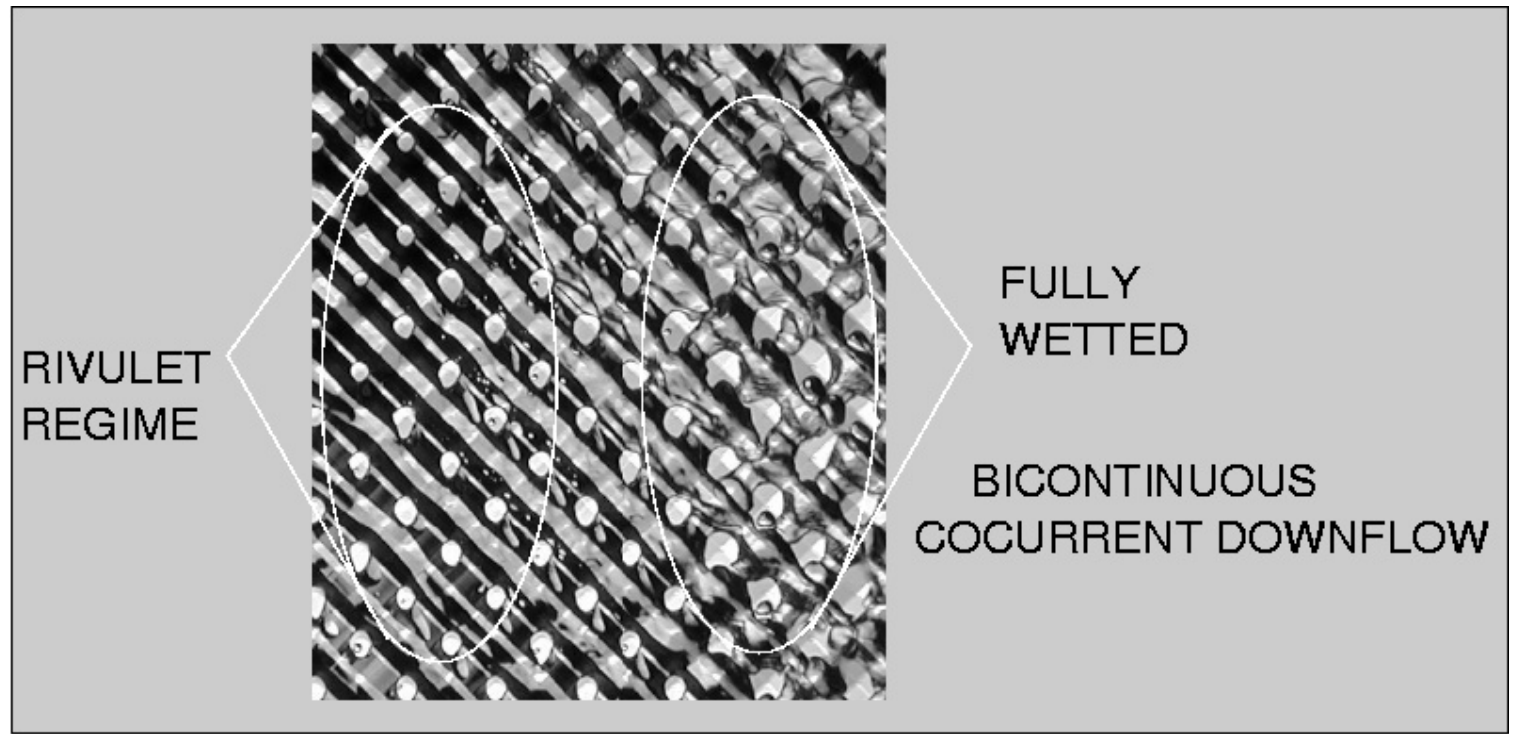

Fig. 5.2: Transition from the rivulet to bicontinuous regime at liquid Reynolds number $\mathscr{N}_{R e}^{\ell}=560\left(u^{l}=180 \mathrm{~m} / \mathrm{h}\right)$ and gas Reynolds numbers $\mathscr{N}_{R e}^{g} \leq 40(F \leq$ $\left.1.710^{-2} \mathrm{~m} / \mathrm{s}\left(\mathrm{kg} / \mathrm{m}^{3}\right)^{1 / 2}\right)$.

in the core of the passages which are formed by a continuous liquid film that flows downward, driven by gravity. The contact points of the crests are filled with a larger volume of liquid, if compared with the rivulet flow regime. These points appear as bright spots in figure 5.3 and form a diamond-shaped pattern. The center of the diamonds is relatively dark because it is a pore body, that is, the region of largest available local volume created by the superposition of two valleys on the opposing plates. Because the valleys are fully covered by a thin liquid film and the core of the pore body is occupied by gas, the light reflects on the air-water interface, creating a shadow darker on the sides of the crimp than on the trough line. This is the reason why the center of the diamond is not uniformly dark. In figure 5.4, a close-up photo reveals ripples on the liquid film at a pore throat, indicating a fully wetted solid surface.

The bicontinuous regime benefits from a greater gas-liquid interfacial area but can only stand a fraction of the gas flow rate of the rivulet regime. This is so because a greater liquid flow rate is required to fully wet the acrylic surface in the bicontinuous regime; therefore, liquid holdup is relatively high. The constrictions at the pore throats are very sensitive to the gas flow rate and tend to "close" as the gas accelerates through the passage. The mechanism of acceleration is similar to a venturi-type effect. As the gas flow rate ramps up, the pore throats are rapidly filled with liquid, forming 


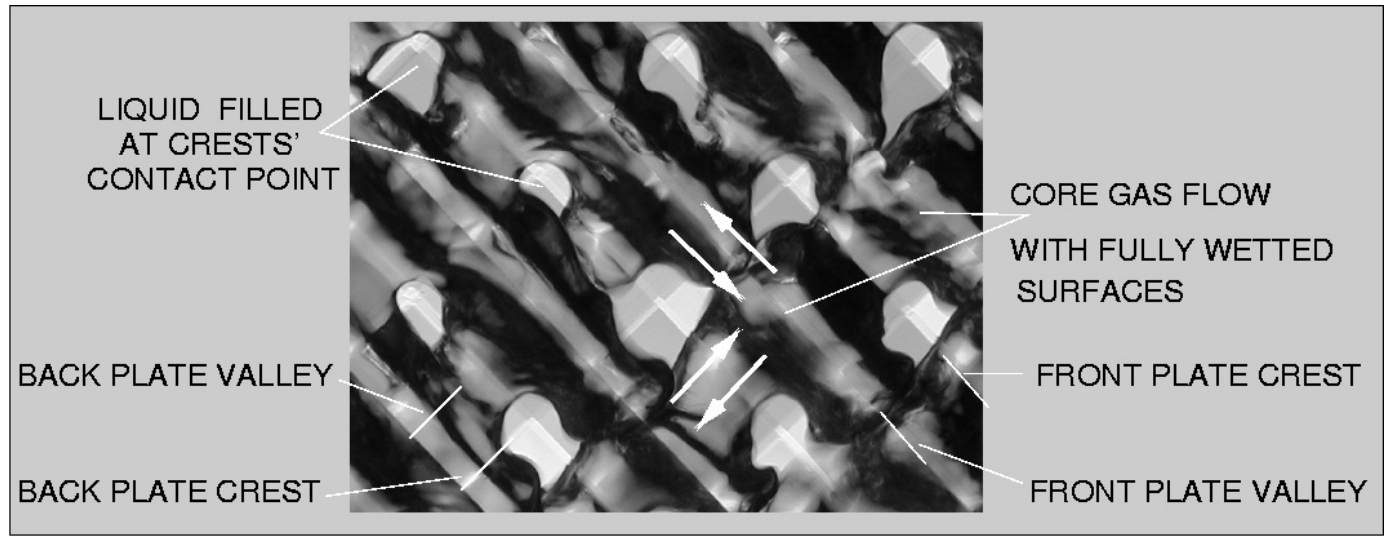

Fig. 5.3: Homogeneous bicontinuous regime at liquid Reynolds number $\mathscr{N}_{R e}^{\ell}=710$ $\left(u^{l}=180 \mathrm{~m} / \mathrm{h}\right)$ and gas Reynolds number $\mathscr{N}_{R e}^{g}=10\left(F=4.210^{-3} \mathrm{~m} / \mathrm{s}\left(\mathrm{kg} / \mathrm{m}^{3}\right)^{1 / 2}\right)$.

a liquid-filled front. The resulting regime is described in the next section.

In summary, the bicontinuous regime features a simply connected network of expanding and contracting passages whose surfaces are fully wetted by the flowing liquid. Accordingly, as the gas counterflows through the network, it undergoes acceleration and deceleration that might incur friction losses similar to those found in random packings. It is well known that in high-liquid-flow services, structured packings lose their efficiency and/or capacity advantage over random packings. This phenomenon may be explained by the fact that friction losses in the bicontinuous regime are similar to those in random packing.

\subsection{Flooding-fronts regime}

The liquid holdup in the pore throats of the bicontinuous regime (fig. 5.5) is extremely sensitive to the gas flow rate because an entire set of throats suddenly fills with liquid when the gas load is raised. The mechanism that causes a pore throat to fill (local phase inversion) parallels that of flooding in annular two-phase flows, except for one subtlety - the passages contract and expand in the direction of the corrugations. The resulting geometry causes the pressure drop to vary quadratically with mean velocity, which holds true for laminar flows. Such an arrangement contrasts with annular flows in straight tubes. The sudden filling of a pore throat is likely to be caused by an interfacial instability driven by the pressure drop in the accelerating gas flow, the shear stress on the liquid surface, and the surface tension.

At liquid Reynolds number $\mathscr{N}_{R e}^{\ell}=710\left(u^{l}=180 \mathrm{~m} / \mathrm{h}\right)$ and gas Reynolds numbers $30 \leq \mathscr{N}_{R e}^{g} \leq 760\left(1.310^{-2} \leq F \leq 3.310^{-1} \mathrm{~m} / \mathrm{s}\left(\mathrm{kg} / \mathrm{m}^{3}\right)^{1 / 2}\right)$ and higher liquid 


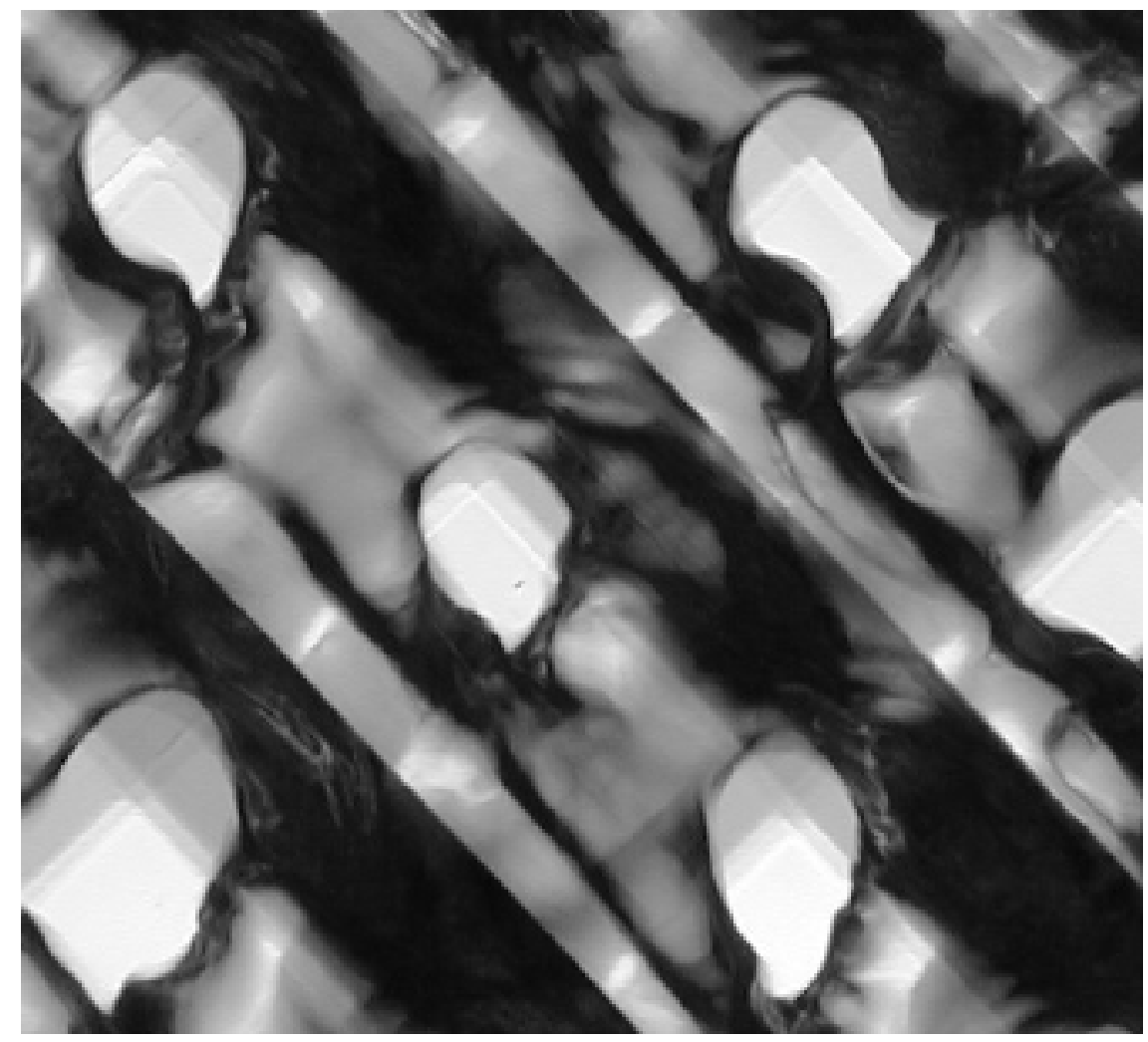

Fig. 5.4: Close-up of bicontinuous regime at liquid Reynolds number $\mathscr{N}_{R e}^{\ell}=710$ $\left(u^{l}=180 \mathrm{~m} / \mathrm{h}\right)$ and gas Reynolds number $\mathscr{N}_{R e}^{g}=10\left(F=4.210^{-3} \mathrm{~m} / \mathrm{s}\left(\mathrm{kg} / \mathrm{m}^{3}\right)^{1 / 2}\right)$ shows ripples on the liquid film, indicating a fully wetted surface. 


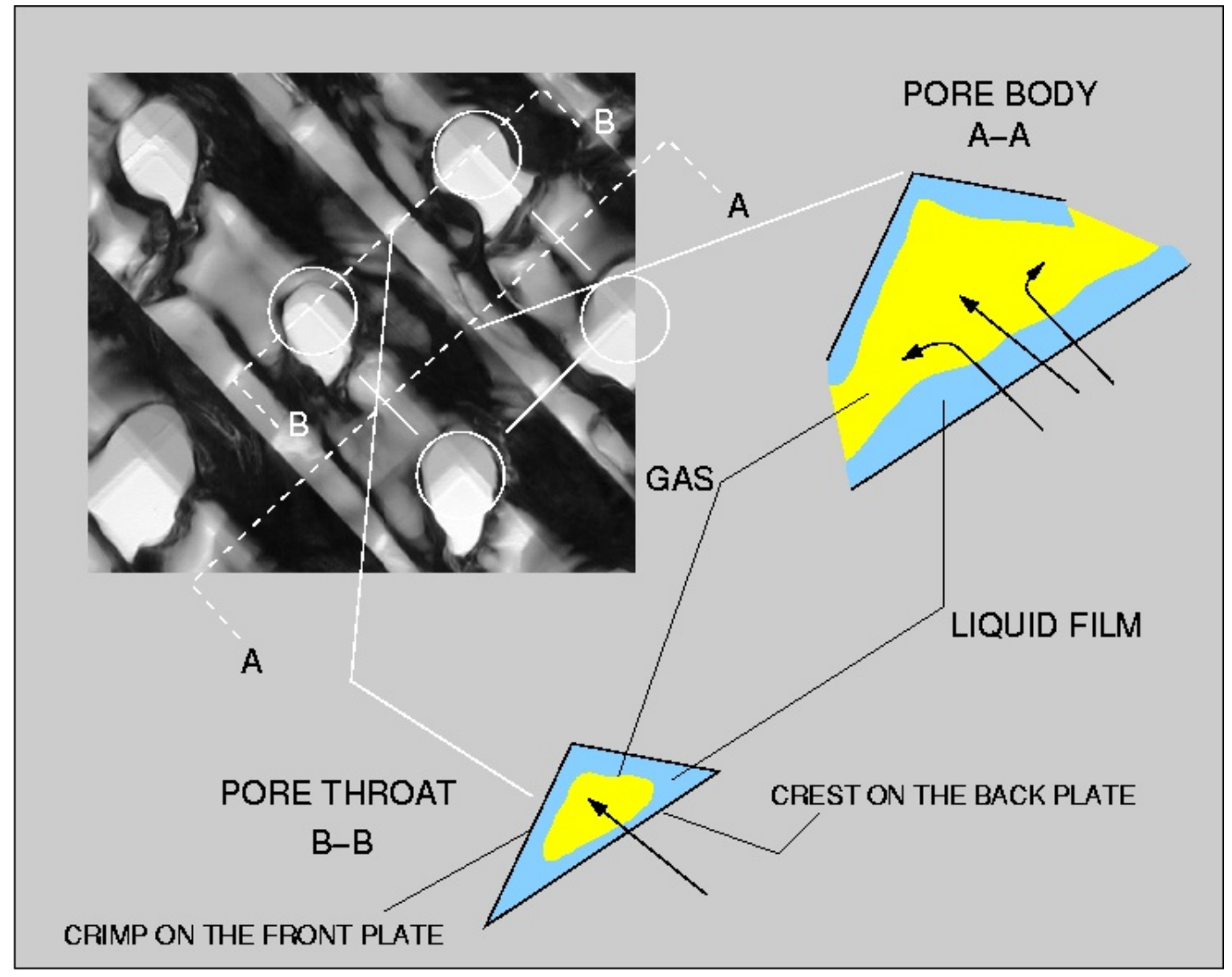

Fig. 5.5: Cross section of a pore throat and a pore body in the bicontinuous regime at liquid Reynolds number $\mathscr{N}_{\text {Re }}^{\ell}=710\left(u^{l}=180 \mathrm{~m} / \mathrm{h}\right)$ and gas Reynolds number $\mathscr{N}_{R e}^{g}=10\left(F=4.210^{-3} \mathrm{~m} / \mathrm{s}\left(\mathrm{kg} / \mathrm{m}^{3}\right)^{1 / 2}\right)$. A pore throat is formed by a crest edge of one plate and a crimp on the opposing plate (section B-B). Similarly, the pore body is formed by a trough edge of one plate and a crimp on the opposing plate (section $A-A)$. 
Reynolds numbers (sec. 5.6), flooding fronts appear. These fronts form by successive pore-throat closure along the crest of the corrugation, and they typically span its entire length. The gas becomes discontinuous, at least as long as the front is stationary. Because a front can effectively block the passage of the gas by extending from one side of the plates to the other, pressure builds up on the gas phase at the lower side of the front, forcing it to move upward normal to itself until the gas finds its way out through the top of the plates (fig. 5.6). Therefore, flooding fronts are often found in motion, sweeping the domain back and forth, parallel to the corrugations and interacting with other fronts.

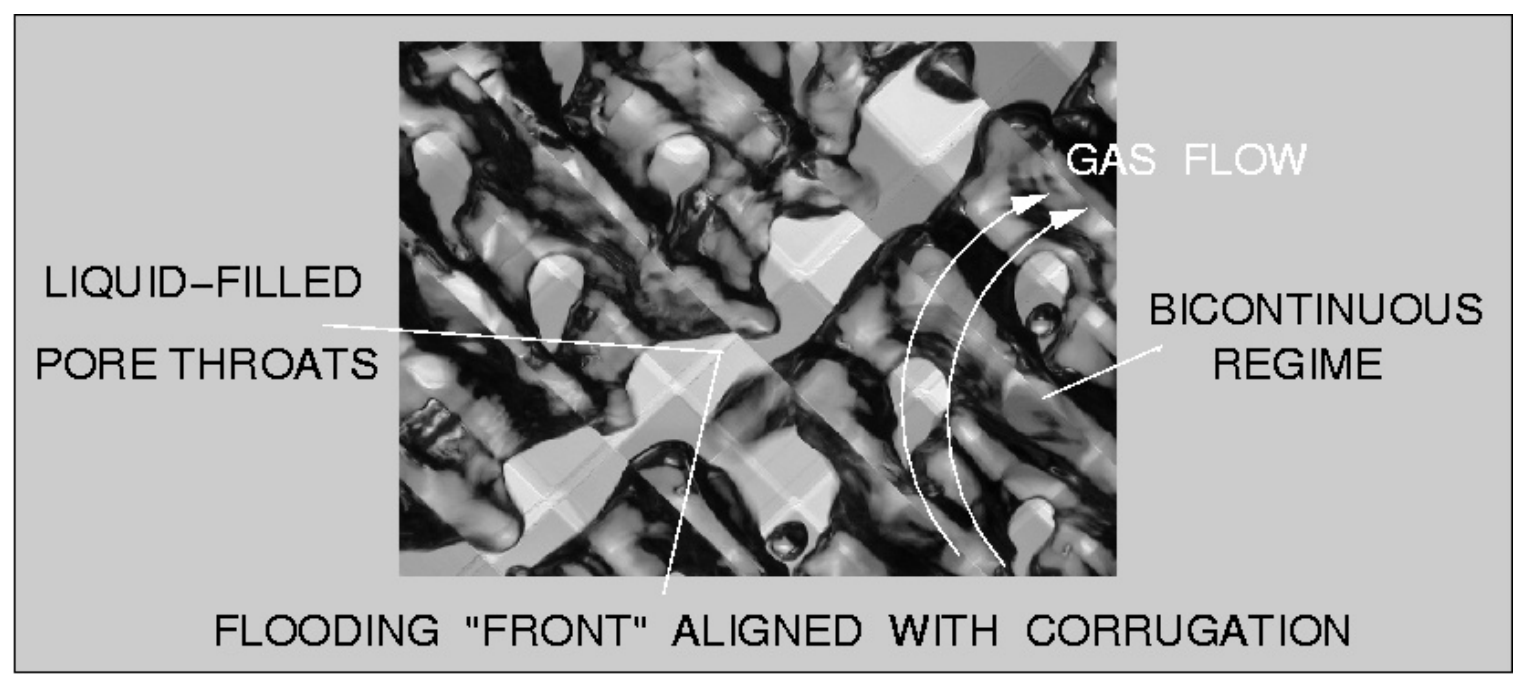

Fig. 5.6: Flooding-fronts regime at liquid Reynolds number $\mathscr{N}_{R e}^{\ell}=1060\left(u^{l}=\right.$ $340 \mathrm{~m} / \mathrm{h})$ and gas Reynolds number $\mathscr{N}_{R e}^{g}=10\left(F=4.210^{-3} \mathrm{~m} / \mathrm{s}\left(\mathrm{kg} / \mathrm{m}^{3}\right)^{1 / 2}\right)$ showing a front (bright stripe from top right to bottom left) blocking the gas flow. The front moves upward normal to itself and is formed by a collection of liquid-filled pore throats.

The flooding-fronts regime is dynamically very rich. The width of the fronts can span a couple of crimp-base lengths, and as the gas load increases, multiple fronts form and travel in different directions. The fronts can also intersect each other and reflect at the boundaries of the plates, generating various patterns (fig. 5.7).

\subsection{Flooding-waves regime}

Another distinctive flow regime appears at sufficiently high liquid flow rates and gas flow rates (sec. 5.6) - the flooding-waves regime. Phase inversion is well established in the flooding-waves regime since the gas phase is notably dispersed. 
Valmor de Almeida \& Cyrus Riahi-Nezhad
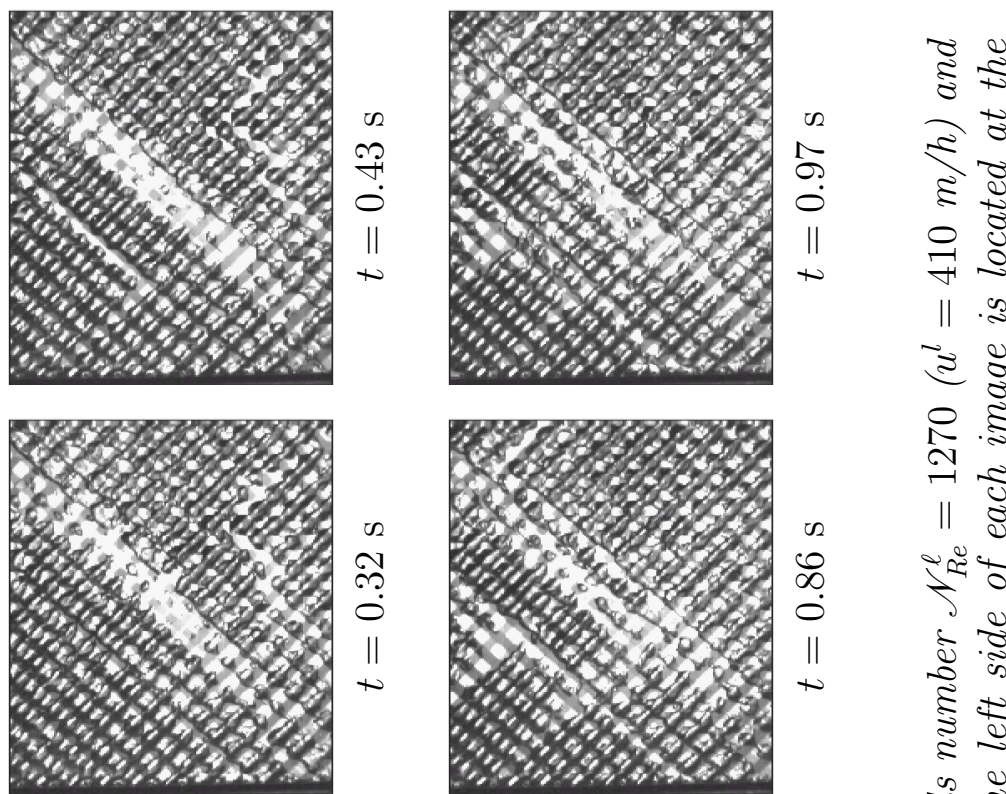

․․ है

i

is
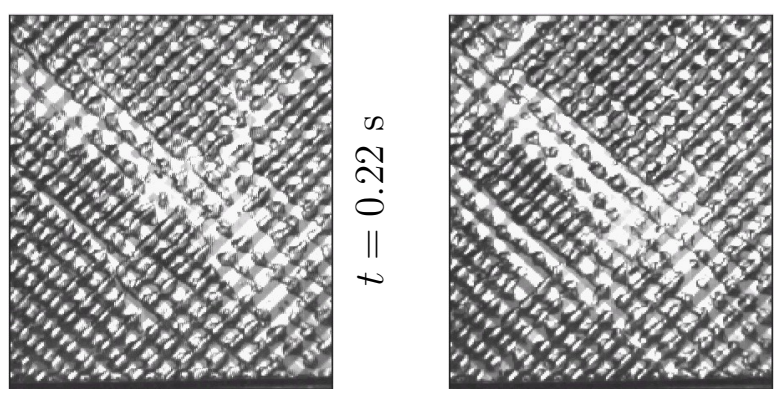

110

स⿺辶

$\therefore \frac{1}{8}$

ปิ क

हิ

क

突

อ จ

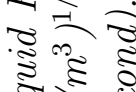

엉 को

$\overrightarrow{0} \leqslant$

है है क

खึ है
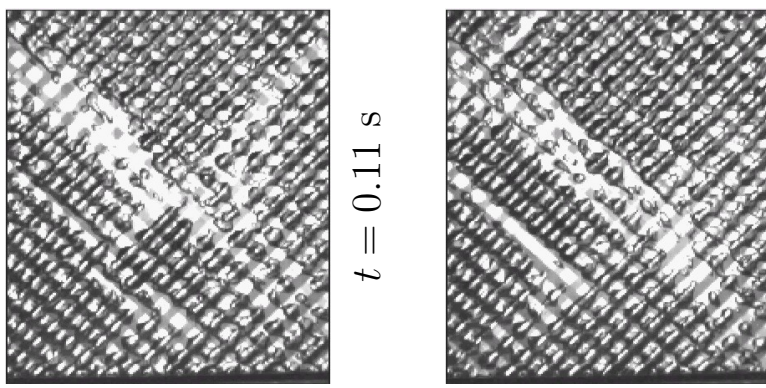

is

है ข

के $\mid 1$ क

:

$\stackrel{2}{\rightarrow} ᄋ$

竝 11 . है

कर से

के

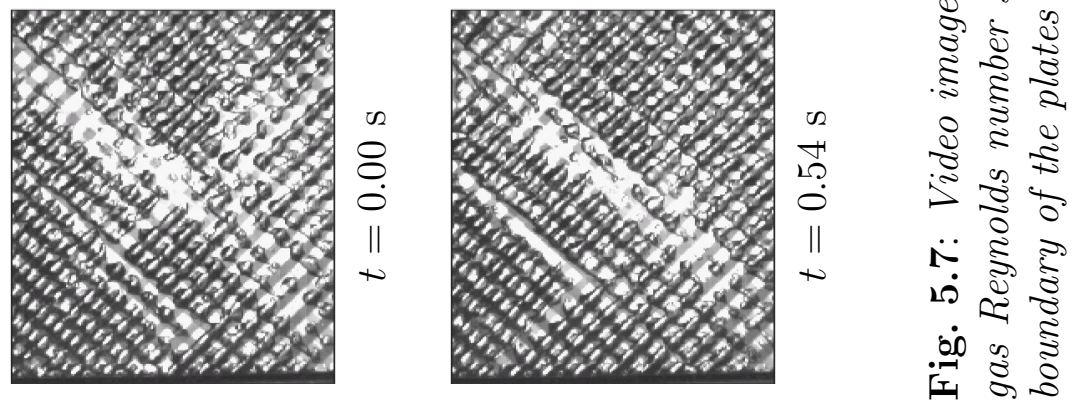

Oak Ridge National Laboratory Technical Report ORNL/TM-2000/101 pp. 1-34 
In the flooding-fronts regime, if liquid and/or gas flow rates are further increased, the width of the fronts begins to span several crimp-base lengths. Greater flow complexity is observed due to the interaction of multiple fronts that merge to form liquidrich waves that do not align with the corrugation geometry. The waves sweep the entire domain in different directions in a disorderly manner not related to the underlying geometry of the corrugated plates (fig. 5.8). In a manner similar to the flooding fronts, the flooding waves are propelled upward by the gas at the lower side of the wave under relatively high pressure. Once the waves reach the top of the plates, drops of liquid may be carried in the exiting air.

A significant feature of the flooding-waves regime is that it always precedes the layer of liquid on the distributor - a symptom often associated with the flood point in packed towers. Because the transition from a flooding-fronts to flooding-waves regime involves a glaring lack of alignment of the fronts with respect to the corrugations, the onset of the latter regime may serve as a detectable signal for defining an operational upper limit for the system.

\subsection{Flow regime map}

Typical values of flow transition are shown in table 5.1. The values are not hard numbers for the following primary reasons. First, as in most flow regime characterizations, the detection of the exact onset of a flow regime by visual means leaves room for subjectivity. Second, the positioning of the distributors at the top of the plates had a small but noticeable effect on the flow regimes, particularly on the rivulet-tobicontinuous transition where wettability effects play a significant role. Consequently, the values in the table are mean values and have a $15 \%$ variation; we acknowledge that the variation can be slightly higher.

\section{Conclusions and final remarks}

Previously unknown flow regimes of air-water counterflow through a pair of vertical cross corrugated parallel plates were observed in this study, namely, rivulet, bicontinuous, flooding-fronts, and flooding-waves regimes. The analysis of these regimes may offer significant scientific insight into the hydraulics and mass transfer of gas-liquid counterflows in chemical contactors that are filled with sheets of corrugated materials.

The corrugated plates used in this experiment were constructed with clear acrylic to permit direct visualization of the flowing phases. The geometry of the corrugation and arrangement of the plates were drawn from modern industrial structured packing models. In addition, the range of flow parameters examined here covered the spectrum of typical liquid loads $\left(58-410 \mathrm{~m}^{3} / \mathrm{h}-\mathrm{m}^{2}, 24-160 \mathrm{gpm} / \mathrm{ft}^{2}\right)$ found in 
Valmor de Almeida \& Cyrus Riahi-Nezhad
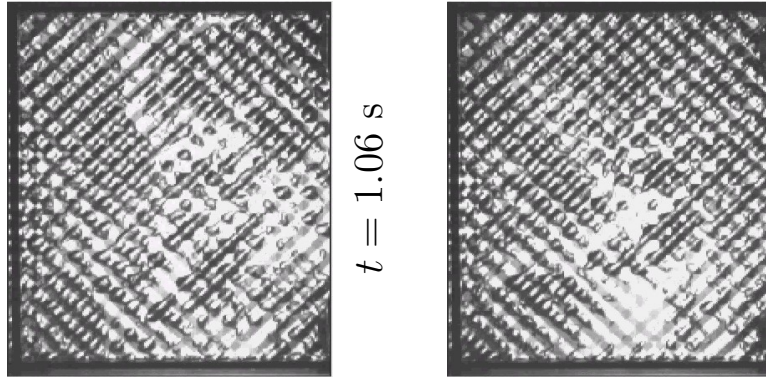

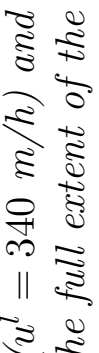
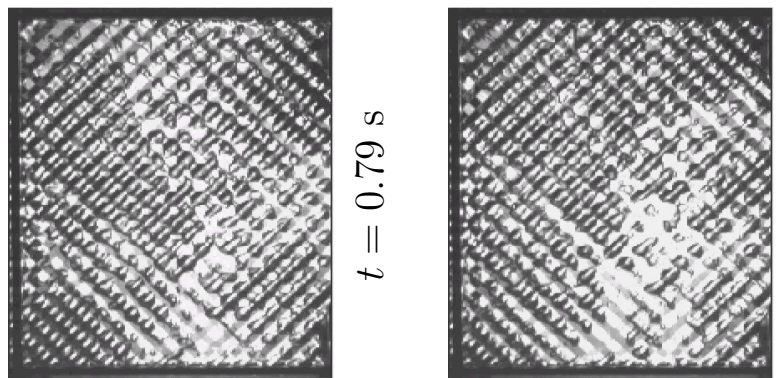

$\begin{array}{ll}0 \\ 0 \\ 0 \\ -1 & 0 \\ \| & 0 \\ 0\end{array}$

รี

i. को

हิ
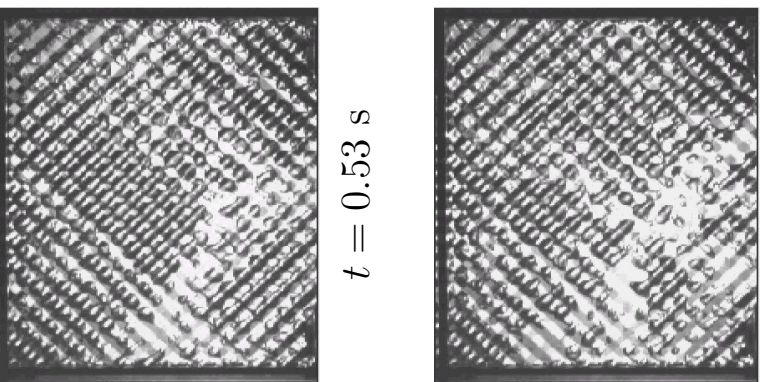

$\begin{array}{cc}0 \\ 0 \\ 0 & 0 \\ 0 & 0 \\ 0 & 0\end{array}$

放

กิ กิ

अิ

క్ష है

$\overrightarrow{0}$

है है

शे

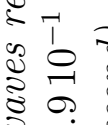

3.

है। ह

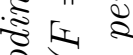

$\stackrel{\circ}{\circ}$ है

ॠ म

क०

की $5 \frac{1}{3}$

है है

요
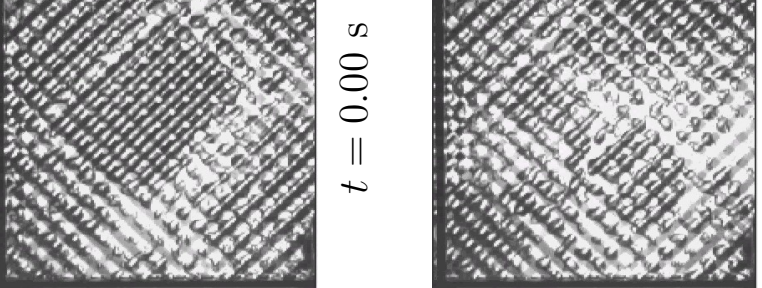

$\infty$
कै
के
+
+

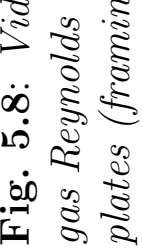

Oak Ridge National Laboratory Technical Report ORNL/TM-2000/101 pp. 1-34 
Table 5.1: Flow regime map. $R$-rivulet, $R / B$-rivulet to bicontinuous transition, $B$-bicontinuous, FF-flooding fronts, $F W$-flooding waves. $F$ is the gas flow parameter in $\mathrm{m} / \mathrm{s}\left(\mathrm{kg} / \mathrm{m}^{3}\right)^{1 / 2}$ (the values in parentheses are measured in $\mathrm{ft} / \mathrm{s}\left(\mathrm{lb} / \mathrm{ft}^{3}\right)^{1 / 2}$ ) and $u^{l}$ is the liquid superficial velocity (or liquid load) in $m^{3} / h-m^{2}$ (the values in parentheses are measured in US gpm/ft.

\begin{tabular}{|cc|cccccc|}
\hline & $\mathscr{N}_{R e}^{g}$ & 20 & 40 & 270 & 350 & 630 & 760 \\
& $F$ & $8.310^{-3}$ & $1.710^{-2}$ & $1.210^{-1}$ & $1.510^{-1}$ & $2.710^{-1}$ & $3.310^{-1}$ \\
$\mathscr{N}_{R e}^{\ell}$ & $u^{l}$ & $\left(6.810^{-3}\right)$ & $\left(1.410^{-2}\right)$ & $\left(9.810^{-2}\right)$ & $\left(1.210^{-1}\right)$ & $\left(2.210^{-1}\right)$ & $\left(2.710^{-1}\right)$ \\
\hline \hline 170 & $58(24)$ & $\mathrm{R}$ & $\mathrm{R}$ & $\mathrm{R}$ & $\mathrm{R}$ & $\mathrm{R}$ & $\mathrm{R}$ \\
350 & $110(48)$ & $\mathrm{R}$ & $\mathrm{R}$ & $\mathrm{R}$ & $\mathrm{R}$ & $\mathrm{R}$ & $\mathrm{R}$ \\
560 & $180(76)$ & $\mathrm{R} / \mathrm{B}$ & $\mathrm{B}$ & $\mathrm{B}$ & $\mathrm{FF}$ & $\mathrm{FF}$ & $\mathrm{FF}$ \\
710 & $230(94)$ & $\mathrm{B}$ & $\mathrm{FF}$ & $\mathrm{FF}$ & $\mathrm{FF}$ & $\mathrm{FF}$ & $\mathrm{FF}$ \\
920 & $290(120)$ & $\mathrm{FF}$ & $\mathrm{FF}$ & $\mathrm{FF}$ & $\mathrm{FF}$ & $\mathrm{FW}$ & $\mathrm{FW}$ \\
1060 & $340(140)$ & $\mathrm{FF}$ & $\mathrm{FF}$ & $\mathrm{FF}$ & $\mathrm{FW}$ & $\mathrm{FW}$ & $\mathrm{FW}$ \\
1270 & $410(160)$ & $\mathrm{FF}$ & $\mathrm{FF}$ & $\mathrm{FW}$ & $\mathrm{FW}$ & $\mathrm{FW}$ & $\mathrm{FW}$ \\
\hline
\end{tabular}


the operation of structured packed towers, particularly in the high-liquid-flow service and also medium-to-low gas flow factors (up to $0.33 \mathrm{~m} / \mathrm{s}\left(\mathrm{kg} / \mathrm{m}^{3}\right)^{1 / 2}$ or up to $\left.0.27 \mathrm{ft} / \mathrm{s}\left(\mathrm{lb} / \mathrm{ft}^{3}\right)^{1 / 2}\right)$.

The rivulet regime comprises a gas-continuous/liquid-discontinuous counterflow. The liquid flows downward driven by gravity, like rectilinear streams attached to the corrugation valleys. A relatively large dry area on the surface of the acrylic is exposed to the upward flow of air. The rivulet is the predominant regime for liquid and gas loads comparable with the normal operation of gas-liquid contractors.

The bicontinuous regime appears at higher liquid loads, and it is characterized by a continuous liquid film that wets the corrugated walls and a continuous gas phase that flows at the core. The distribution of the phases is quite subtle. The liquid forms a network of contracting-expanding passages, resulting in a fully connected set of pore bodies and pore throats. Because of successive acceleration and deceleration of the gas in the passages, friction losses can be similar to those experienced in random packing, which confirms that structured packings have reduced advantage over random packings on high-liquid-flow services.

At increased gas/liquid loads, the acceleration of the gas through the pore throats of the bicontinuous regime causes the liquid to choke the passage. The blocking mechanism is akin to the collapse of two-phase annular counterflows. It is observed that many of these pore throats rapidly flood along a corrugation crest, forming a front. The emergence of flooding fronts marks the onset of phase inversion, where the gas is the discontinuous phase. We named this regime as flooding-fronts regime.

The flooding-waves regime becomes visible as the flooding fronts merge and form liquid-rich regions not aligned with the corrugations. This regime occurs at high liquid loads and consistently precedes the buildup of liquid on the distributor - a symptom used to identify the flood point in gas-liquid contactors. In view of the distinctive flow pattern of the flooding-waves regime, we speculate that it can serve as a practical means of detecting an operational upper limit for gas-liquid countercurrent flow services.

The flow regimes featured in this work are likely to be realistic representations of flow patterns that exist at the packing level within industrial structured packed towers. In fact, it is conceivable that all of the regimes take place simultaneously at different locations within a tower by virtue of maldistribution. For instance, a tower operating at low-liquid-flow service may have the flooding-waves regime (a local highliquid-flow regime) in some of the corrugated sheets. Therefore typical values of flow parameter liquid load (superficial velocity) and gas flow factor based on quantities and dimensions of the packed tower cannot in general be directly compared with similar flow parameters presented in this work for a pair of parallel plates. Such comparison seems reasonable, however, if the gas-liquid flow regime in the tower can be assumed homogeneous.

Oak Ridge National Laboratory Technical Report ORNL/TM-2000/101 pp. 1-34 
Last but not least, we have presented a well-defined experiment which should serve as an invaluable aid in the development of improved first-principles modeling of gas-liquid countercurrent flows in general and, in particular, in modeling of flows characteristic of structured packed-tower operation.

\title{
Acknowledgments
}

This work was supported by the Division of Chemical Sciences, Office of Basic Energy Sciences, U.S. Department of Energy under the contract DE-AC05-00OR22725 with UT-Battelle, LLC. The authors wish to thank Dr. David DePaoli and Dr. Jack Watson for discussions related to this research.

\author{
OAK Ridge National Laboratory \\ P.O. Box 2008 \\ OAk Ridge, Tennessee, TN 37831-6224 \\ U.S.A. \\ E-mail: dealmeidav@ornl.gov
}

\section{References}

Blomerius, H., Hölsken, C., And Mitra, N. K. 1999 Numerical investigation of flow field and heat transfer in cross-corrugated ducts. ASME Journal of Heat Transfer 121 314-21.

Cavatorta, O. N., Böhm, U., and de del Giorgio, A. M. C. 1999 Fluiddynamic and mass-transfer behavior of static mixers and regular packings. AIChE J. 45 938-48.

DE Almeida, V. F. 1995 Gas-Liquid Counterflow through Constricted Passages. Ph.D. dissertation, University of Minnesota, Department of Chemical Engineering and Materials Science. Requests to dealmeidav@ornl.gov or at URL: http://www-smpr.ct.ornl.gov/ ${ }^{\text {dalmeida. }}$

DE Almeida, V. F. 2000 Air-water counterflow through cross corrugated parallel plates: mass transfer. Technical Manuscript ORNL/TM-2000-, Oak Ridge National Laboratory, Oak Ridge, TN 37831-6224, U.S.A. In preparation.

Focke, W. W. And KnibBe, P. G. 1986 Flow visualization in parallel-plate ducts with corrugated walls. J. Fluid Mech. 165 73-7. 
Kister, H. Z. 1992 Distillation Design. McGraw-Hill, New York, New York.

Melli, T. R., de Santos, J. M. A., Kolb, W. B., And Scriven, L. E. 1990 Cocurrent downflow in networks of passages microscale: Roots of macroscale flow regimes. Ind. Eng. Chem. Res. 29 2367-79.

Stichlmair, J. G. And Fair, J. R. 1999 Distillation: Principles and Practices. Wiley-VCH, New York, New York. 